CHAPTER 19

\title{
Fouling Control of Membranes with Pretreatment
}

\author{
Wenshan Guo, Huu-Hao Ngo and Saravanamuthu Vigneswaran
}

The impediment of the membrane technology is the fouling problem and consequently higher operating and membrane replacement cost. Pretreatment is very important for developing the best treatment process train to secure better membrane treatability and producing acceptable effluent qualities. This chapter addresses the state of the art pretreatment techniques and their applications to low pressure (MF/UF) and high pressure $(\mathrm{NF} / \mathrm{RO})$ membranes in water and wastewater treatment as well as desalination. The impacts of different pretreatment processes on membrane performance and membrane fouling control have been extensively reviewed.

\subsection{Introduction}

Application of membrane technology has expanded over the last decades for advanced water and wastewater treatment. Particularly, membrane bioreactors (MBRs) for separation and retention of biological solids have been widely applied as one of the alternatives to conventional treatment processes. However, as various factors govern the operating cost of a membrane system, such as power requirements, power cost, labor cost, material cost, membrane cleaning costs, scale inhibition costs, membrane life and replacement cost, some limitations remain in using membranes for water and wastewater treatment (Bennett, 2005). The major obstacle for the application of membrane processes is the rapid decline of the permeate flux over time as a result of membrane fouling. That is to say, without proper pretreatment, rapid membrane fouling (or clogging) may occur, which will reduce permeate flux, increase feed pressure, reduce productivity, increase system downtime, increase membrane maintenance and operation costs due to membrane cleaning, and decrease the lifespan of the membrane modules (Bai and Leow, 2002; Seidel and Elimelech, 2002). 
Therefore, better understanding and minimization of membrane fouling is not only the key problem to be resolved, but also one of the main factors driving membrane technology forward. At present, the approaches to identify the best practices to minimize capital and operation costs for water industry are as follows (Bennett, 2005):

- $\quad$ Effective piloting and improved warranties on membrane lifespan guarantee long-term performance.

- $\quad$ Less membrane area in installed systems leads to less chemical required to clean the membranes, and systems can be designed to operate at lower net driving pressure (NDP) with reduced component costs such as pumps, pipework and pressure vessels.

- $\quad$ Advances in process monitoring techniques enable the accurate interpretation of normalized operating data from membrane systems so that cleaning can be undertaken on the basis of process requirements rather than as timed intervals.

- $\quad$ Additional pre- and post-treatment can improve membrane performance, whereas costs may be required depending on the particular application.

\subsection{Membrane Fouling}

Membrane systems can be operated in either constant permeate flux (flow rate per unit membrane area, $\mathrm{L} / \mathrm{m}^{2} \cdot \mathrm{h}$ ) with variable transmembrane pressure (TMP) or constant TMP with variable permeate flux. The former mode is the common one. Based on the operating TMP, membranes for water treatment and reuse can be broadly categorizes as low pressure membranes (LPMs) and high pressure membranes (HPMs). LPMs include microfiltration (MF) and loose ultrafiltration (UF) membranes, which are operated at relatively low TMPs, typically less than 100 to $200 \mathrm{kPa}$. On the other hand, HPMs such as tight UF, nanofiltration (NF) and reverse osmosis (RO) membranes are operated at relatively high TMPs $(>200 \mathrm{kPa})$.

Membrane fouling occurs during an increase in TMP to maintain a particular flux or during a decrease in flux when the system is operated at constant pressure (Jacangelo et al., 1998). Membrane fouling can be classified as reversible fouling and irreversible fouling, of which the distinction is entirely dependent on the context in which membranes are operated and cleaned. Reversible fouling (including backwashable and non-backwashable) occurs due to the cake layer or concentration polarization of materials at the membrane rejection surface. Membrane with backwashable reversible fouling can be restored through appropriate physical washing protocol such as backwashing or hydrodynamic scouring (surface washing), while the non-backwashable reversible fouling only can be removed by chemical cleaning. Irreversible fouling occurs by chemisorption and pore plugging mechanisms. In case of irreversible fouling, the loss in transmembrane flux cannot be recuperated hydrodynamically or chemically. This 
means that the membranes must go through extensive chemical cleaning or be replaced (Guo, 2005; AWWA, 1992).

Fouling of membranes is caused by complex physical and chemical interactions between various fouling constituents in the feed and between these constituents and the membrane surface. Mass transport can lead to the attachment, accumulation, or adsorption of materials onto membrane surfaces and/or within membrane pores. Previous studies have demonstrated that membrane fouling and the characteristics of foulants are determined by feed water composition, the concentration of the major constituents, water chemistry ( $\mathrm{pH}$, ionic strength, and divalent cation concentration), membrane properties (surface morphology, hydrophobicity, charge and molecular weight cut-off), temperature, mode of operation and hydrodynamic conditions (initial permeate flux and crossflow velocity) (Li and Elimelech, 2004). Hence, any factors that could change the hydrodynamic characteristics of membrane modules and the chemical characteristics of feed waters would affect the overall membrane performance (Zhou and Smith, 2002). Consequently, the combined physical and chemical effects will control the degree of attachment, as well as will determine how severe the fouling is and what strategies will be effective in controlling it (Pearce, 2007a). Normally, foulants can be classified into the following four categories:

- Particulates: inorganic or organic particles/colloids act as foulants which can physically blind the membrane surface and block the pores, or hinder transport to the surface by the development of a cake layer;

- Organic: dissolved components and colloids (e.g., humic and fulvic acids, hydrophilic and hydrophobic materials and proteins) which would attach to the membrane by adsorption;

- Inorganic: dissolved components (e.g., iron, manganese and silica) which tend to precipitate onto the membrane surface due to $\mathrm{pH}$ change (scaling) or due to oxidation (e.g., iron or manganese oxides). Coagulant/flocculant residuals may also be present as inorganic foulants;

- Micro-biological organisms: the microbiological category covers vegetative matter such as algae and microorganisms (e.g., bacteria), which can adhere to the membranes and cause biofouling (biofilm formation).

Raw waters contain a wide distribution of materials that can cause membrane fouling, such as fine particles, dissolved organic compounds, colloids, less soluble salts and nutrients for biological growth. Fouling by different foulants can be considered to occur by different mechanisms. Recent research has identified six principal fouling mechanisms: (a) pore blocking; (b) cake formation; (c) concentration polarization; (d) organic adsorption; (e) inorganic precipitation; and (f) biological fouling. 


\subsection{Pretreatment for Membrane Processes}

\subsubsection{Methods for Membrane Fouling Control}

Regardless of using different cleaning techniques, previous studies for membrane fouling control carried out in various areas can be classified into the following categories: (a) fouling control by operating the membrane system below critical flux or use antiscalants/antifoulants; (b) anti-fouling membranes and modules to modify hydrodynamic conditions of feed flow or modify membrane surface properties; and (c) pretreatment technologies to remove/modify the properties of fouling potential components in feed water before they passes through the membrane (Guo 2005; Sheikholeslami, 1999).

In membrane fouling mechanism, there always has an induction period before fouling occurs. The induction period is a function of the system and operating condition. Therefore, there exists a critical flux, below which fouling resistance remains negligible. Controlling the flux at a sub-critical level can avoid cake formation and mitigate membrane fouling. However, due to the complexity of the filtration systems (e.g., submerged membrane systems or filtration of a pretreated effluent), it is more appropriate to use the term 'sustainable flux' which is conveniently defined as the flux that allows acceptable operating period without the need for cleaning (Fane et al., 2002). Sustainable flux, salinity, $\mathrm{pH}$, cross flow velocity, temperature, pressure, repulsion forces and type of particles are all factors which affect stability of colloidal particles. Another method for fouling control is the use of antiscalants or antifoulants. They act as scale inhibitors, particulate dispersants, scale crystal modifiers or sequestrates (for $\mathrm{Fe}$, $\mathrm{Mg}$, etc.). However, considering the safety/environmental aspects and cost, it seems that research in this area is very limited.

There have been numerous efforts to develop membrane and modules that are resistant to fouling. The first feature is modifying the feed flow or physical properties to improve the dynamic conditions of flow distribution. This helps to reduce the boundary layer thickness at the membrane surface and enhance both membrane flux and apparent rejection. The second approach is modifying the membrane properties. Membrane surface modification attempts to change the physical and chemical properties of the surface to reduce primary fouling and adsorption of molecules (e.g., thin film composite membranes, pre-coated membranes and dynamic membranes). The last achievement is the module and spacer design. Module and spacer design results in a module with better packing, higher density and easy cleaning. It affects the performance and fouling propensity of membrane systems by improving the hydrodynamics of flow and contact time. 
Since the fouling takes place on the membrane during operation, there is a need for fouling control at this stage. More frequent cleaning usually associates with increased downtime, increased labor and chemical costs and potential degradation of membranes. So far, although periodic backwashing and less frequent chemical cleaning are necessary to remove cake layers and clean blocked membrane pores as well as maintain stable performance of membrane and restore the flux, they decrease the overall performance due to a net loss of permeate. Even if only a small portion of the particles enters the pores, they can significantly contribute to pore blocking on a longer time scale, since their removal during backwash is usually incomplete and they can accumulate over time. For the clearing of blocked pores and the removal of the cake layer, an exponential function of time and back flushing flux is used (Broeckmann et al., 2006). Therefore, at present, the most common approach for membrane fouling reduction is pretreatment that can modify the properties of feed water before it passes through the membrane.

\subsubsection{Impacts of Pretreatment}

Pretreatment to membrane refers to different operations or processes that (a) are conducted prior to or upstream of membrane filtration, (b) effectively modify the feedwater quality and properties of certain aquatic constituents, and (c) improve the filterability of membranes (Huang et al., 2009). In principle, pretreatment can impact the membrane process through altering the following properties of source water:

- Physical: Pretreatment can alter contaminant size distributions and shift membrane fouling from pore constriction or blocking to cake filtration that usually less severe and more reversible.

- Chemical: Pretreatment can change mutual affinities of contaminants or their affinities to membrane surfaces, thereby alleviating irreversible membrane fouling.

- Biological: Pretreatment can remove biodegradable contaminants relevant to membrane biofouling, as well as suppress undesirable microbial growth or reduce pollutant loading on membranes.

As different pretreatments usually preferentially remove certain types of foulants, they have different effects on membrane fouling control. Adsorption, coagulationflocculation $(\mathrm{CF})$, oxidation and prefiltration are common pretreatment methods used for LPMs. Table 19.1 summarizes the mechanisms and effects of these pretreatments (Huang et al., 2009). Besides, sedimentation, dissolved air flotation (DAF), ion exchange and integrated pretreatment processes are also widely used. With regard to HPMs, pretreatment is required to increase the efficiency and lifespan of the membrane elements by minimizing fouling, scaling and degradation of the membranes. A number of potential pretreatment options are also available to guarantee a good and constant performance of NF and RO systems (AMTA, 2010): 
Table 19.1 List of the mechanisms, effects and applications of major pretreatments for membrane filtration processes (Huang et al., 2009).

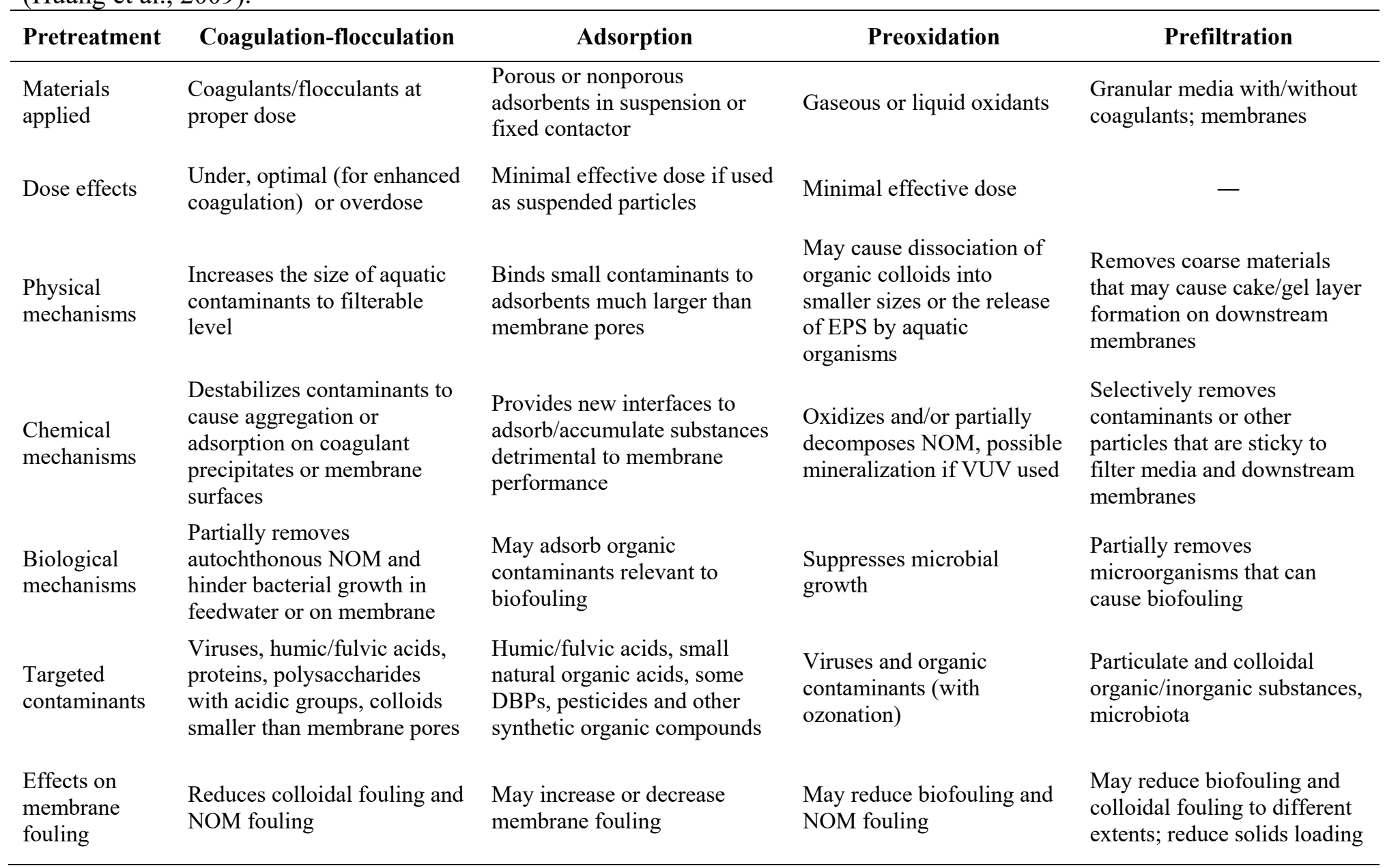


- $\quad$ Flocculants/polymers: to be added as a part of the CF process to improve solid and organic removal. However, overdose may lead to membrane element fouling by iron flocs.

- $\quad$ Scale Inhibitors: to allow new compounds to be formed with better solubility properties and reduce crystal formation by absorbing to the surface of the microcrystals.

- $\quad$ Antifoulants: to help to stabilize metal ions and disperse metal oxides such as iron and manganese as well as colloidal particles thereby reducing inorganic and colloidal fouling.

- $\quad$ Acids: to lower $\mathrm{pH}$ and therefore reduce scaling potential of some compounds such as carbonates.

- $\quad$ Bisulfites: to prevent biogrowth and retard biofilm formation, chloramine can be used as disinfectant. However, Overfeeding will cause degradation of thin film composite membrane elements. Bisulfites are widely used to remove chlorine from water prior to $\mathrm{RO}$ where it could damage the membranes.

- $\quad$ Ozone/UV: to remove organic matter and reduce biological activities.

- $\quad$ Sedimentation/clarifier: To reduce suspended solids.

- $\quad$ Cartridge filters (1-5 microns): to protect membrane elements and serve as the final barrier to water-born particles. For most municipal RO systems, cartridge filters should be a minimum pretreatment, even for the cleanest groundwater sources.

- Media filtration: to remove suspended particles and organics, as well as control biological activities.

- $\quad$ Activated carbon: to minimize membrane fouling and remove organic matter.

- Full conventional plant (coagulation, flocculation, sedimentation and media filtration): to remove particulates, organics and control biological activities.

- $\quad \mathrm{MF} / \mathrm{UF}$ : as a part of an integrated membrane system to remove particulate and bacteria while reduce organic matter.

Schippers et al. (2004) also compiled preferable pretreatment technologies on controlling different types of $\mathrm{NF} / \mathrm{RO}$ membrane fouling in surface water applications (Table 19.2).

\subsubsection{Activated Carbon Adsorption}

Adsorption is a mass transfer process by which a substance (adsorbate) is transferred from the liquid phase to the surface of a solid (adsorbent), and becomes bound by physical and/or chemical interactions. The most usual adsorbents for water treatment are activated carbons. Activated carbon adsorption is utilized in a wide range of industrial, municipal and domestic applications, including water and wastewater purification, liquid and gas purification, precious metal recovery, personnel protection 
and a range of environmental applications. Activated carbon can be produced in powdered (pulverized), granular or extruded (palletized) forms. The choice of the carbon normally depends upon specific applications. The two common forms of activated carbon used in water treatment are powdered activated carbon (PAC) and granular activated carbon (GAC). In liquid-phase adsorption, the adsorption capacity of activated carbon for aromatic compounds depends on a number of factors such as the physical nature of the adsorbent (pore structure, ash content, functional groups, depending on its precursor material and preparation method), the nature of the adsorbate (its solubility, dissociation constant, functional groups present, polarity, molecular weight, size) and the solution conditions ( $\mathrm{pH}$, ionic strength, adsorbate concentration, oxygen availability) (Busca et al., 2008; Kurniawan et al., 2006; Guo, 2005).

Table 19.2 Effects of different pretreatments on NF/RO membrane fouling.

\begin{tabular}{ll}
\hline Fouling type & Preferable pretreatment \\
\hline Particulate & SSF, CS, CSF, MF, UF, BAC \\
Organic & SSF, IC, CS, CSF \\
Inorganic & Scale inhibitor, acid addition \\
Biological & SSF, BAC, Chloramine dosage \\
\hline
\end{tabular}

$\overline{\mathrm{SSF}}=$ slow sand filtration; $\mathrm{CS}=$ coagulation-sedimentation; $\mathrm{CSF}=$ coagulation-sedimentationfiltration; $\mathrm{BAC}=$ biological activated carbon; IC = In-line coagulation.

Two standard types of liquid phase carbon adsorption are fixed-bed and movingbed systems. The fixed-bed system is primarily used for low-flow wastewater streams. On the other hand, moving-bed carbon adsorption systems can operate continuously with wastewater typically being introduced from the bottom of the column. GAC has been successfully applied to fixed-bed filter systems for reduction of organic contaminants and membrane fouling (Wend et al., 2003). Recently, more studies have been focused on combination of PAC adsorption with LPM separation processes (either in the pretreatment step prior to membrane operation or in combination with membrane in the same reactor) because membrane can provide a positive barrier to both suspended solids and PAC (Jirankova et al., 2007). However, the overall impact of PAC on membrane fouling sometimes can be adverse due to association and plugging of aquatic colloids in PAC cakes. As a results, the performance of the membrane-adsorption processes depend on system configuration, operating modes, carbon type, carbon dose, carbon adsorptive characteristics and influent characteristics.

Zularisam et al. (2006) reviewed that PAC has been found to reduce both cake deposition and dissolved organic carbon (DOC) adsorption of dissolved foulants on the membrane. PAC helps to improve hydraulic properties of cake by increasing its permeability and reducing compressibility, thereby decreasing hydraulic resistance and 
irreversible fouling of the membrane. Guo et al. (2005a) also reported dissolved organic compounds which normally can pass through the MF were pre-adsorbed onto PAC particles in a single submerged membrane adsorption hybrid system (SMAHS). In this system, the PAC together with adsorbed organics was then separated by the membrane filtration process. Thus, the addition of PAC can enhance membrane performance by: (a) provide better physical removal of natural organic matter (NOM) and disinfection byproducts (DBPs) and better degradation of organic foulants; (b) reduce the direct loading of dissolved organic pollutants onto the membrane; and (c) prevent membrane fouling and reduce irreversible fouling.

\subsubsection{Coagulation-flocculation (CF)}

As one of the most effective physical-chemical processes, CF has been employed in removing turbidity, colloids, high molecular weight (MW) organic matter and heavy metals. The CF technology consists of the coagulation process destabilizing colloidal particles by the addition of a coagulant and the flocculation process to increase the particle size. Coagulation is usually followed by flocculation of the unstable particles into bulky flocs so that they can settle more easily. The four distinct mechanisms of CF include double layer compression, adsorption and charge neutralization, sweep coagulation and interparticle bridging (Amirtharajah and O'Melia, 1991).

To improve the filtration performance of the membrane, preflocculation or inline flocculation of the feed water using flocculants can modify the way that the suspended solids deposit on the membrane, and thereby improving the membranes performance. The use of flocculants such as alum, ferric salts and polyaluminum chlorides have been previously applied in industrial wastewater treatment as part of the precipitation to remove insoluble metals. The treatment approach has also been evaluated as a flux enhancing agent to reduce color or to reduce phosphorous in wastewaters. Moreover, CF of colloidal material and NOM can reduce the rate of fouling through: (a) increasing particle size by aggregating fine particles and reducing foulant penetration into membrane pores; (b) improving cake permeability by forming less dense and highly porous flocs; and (c) enhancing precipitation/adsorption of dissolved matter into flocs. In addition, CF can also be used to assemble microorganisms with coagulated matter though it is not as effective as other disinfectant agents. Thus, aluminium-based or ironbased flocculants have long been used to remove NOM in the conventional treatment. Nevertheless, although CF pretreatment prior to membrane filtration can be used to enhance permeate quality, it can only reduce the rate of reversible fouling but not the irreversible fouling of low MW polysaccharide compounds. Flocculants use may also provide additional removal of organic matter which may also contribute to membrane fouling. After preflocculation, the pretreated water can be directly filtered through either a membrane or conventional media filtration before membrane filtration (Fan et al., 2008; Zularisam et al., 2006; Guo, 2005). 
The flocculants (coagulants) used in water and wastewater treatment normally contain positively charged ions because most of the difficult particles to be removed from water are negatively charged. Aluminum sulfate $\left(\mathrm{Al}_{2}\left(\mathrm{SO}_{4}\right)_{3} \cdot 14\left(\mathrm{H}_{2} \mathrm{O}\right)\right)$, ferric chloride $\left(\mathrm{FeCl}_{3}\right)$, ferric sulfate $\left(\mathrm{Fe}_{2}\left(\mathrm{SO}_{4}\right)_{3}\right)$, ferrous sulfate $\left(\mathrm{Fe}_{2}\left(\mathrm{SO}_{4}\right)_{3} \cdot 7\left(\mathrm{H}_{2} \mathrm{O}\right)\right)$, aluminum polymers (including polyaluminum chloride $(\mathrm{PACl})$ and polyaluminum sulfates), cationic polymers (synthetic polyelectrolytes), biopolymer (Chitosan), starch, sodium aluminate $\left(\mathrm{Na}_{2} \mathrm{Al}_{2} \mathrm{O}_{4}\right)$, sodium silicate $\left(\mathrm{Na}_{2} \mathrm{O} \cdot\left(\mathrm{SiO}_{2}\right)_{\mathrm{x}}\right)$ are commonly used flocculants. Some previous studies showed that the extensive use of flocculants in conjunction with membrane processes can reduce or even to eliminate internal clogging of the membrane by depositing and stabilizing the colloidal particles, help to form sufficiently large aggregates to realize higher flux rates, lower specific cake resistance, remove soluble microbial products (SMP) and extracellular polymeric substances (EPS) by charge neutralization and bridging, and improve the removal of NOM (especially hydrophobic fraction), DBPs and their precursors (Koseoglu et al., 2008; Bérubé et al., 2002; Kim et al. 2001; Al-Malack and Anderson, 1996). However, improper use flocculants may have adverse effects on membrane fouling because the effectiveness of $\mathrm{CF}$ depends on $\mathrm{pH}$, mixing conditions, flocculant dose and raw water characterizations. Without optimal conditions, flocculants can lead to severe fouling, plugging of lumens of the membrane, diminished effluent quality, increased chemical costs through routine overdosing, reduce sludge digestibility. Besides, the cost of sludge treatment and disposal is a problem in the application of CF (Capar et al., 2006).

\subsubsection{Chemical Oxidation and Advanced Oxidation}

Chemical oxidation was initially utilized in conventional water treatment plants as aid to CF. Various oxidants such as ozone, chlorine, chlorine dioxide or potassium permanganate $\left(\mathrm{KMnO}_{4}\right)$ have been used to suppress the growth of microorganisms, maintain oxidative conditions in the water, and increase assimilable organic carbon that may be removed by downstream filters (Crittenden et al., 2005; Singer and Reckhow, 1999). During the research and development, ozone has attracted more attention than other oxidants owing to concerns over chlorine DBP formation, despite ozone does form its own DBP (bromate). Other applications of chemical oxidation in conventional water treatment include removal of taste and odour, iron and manganese (Farahbakhsh et al., 2004; Ellis et al., 2000).

Although biological treatment has been developed intensively due to its cost effectiveness and versatility in handling a wide variety of organic pollutants, biological treatment processes do not always give satisfactory results, especially when applied to the treatment of recalcitrant, toxic or bio-resistant pollutants (Klavarioti et al., 2009; Mantzavinos and Psillakis, 2004; Huang et al., 1993). Thus, chemical oxidation technologies are often employed for the treatment of complex industrial or hazardous 
effluents that are not amenable to conventional biological methods. Advanced technologies based on chemical oxidation have been developed over the past 30 years in

order to provide viable options for decontaminating wastewaters, enhancement of biodegradability, removal of pathogens and persistent, endocrine-disrupting pharmaceutical residues from municipal WWTP effluents, removal of micropollutants, as well as conditioning and stabilization of biological sludge from WWTPs. The most common advanced oxidation processes (AOPs) can be broadly defined as aqueous phase oxidation methods based primarily on the intermediacy of hydroxyl radicals as oxidant in the mechanisms leading to the destruction of the target compound. Key AOPs include heterogeneous and homogeneous photocatalysis based on near ultraviolet (UV) or solar visible irradiation, photocatalysis $\left(\mathrm{TiO}_{2}\right.$ or other semiconductors), electrochemical oxidation (EC), ozonation $\left(\mathrm{O}_{3}\right)$, hydrogen peroxide $\left(\mathrm{H}_{2} \mathrm{O}_{2}\right)$, Fenton's reagent $\left(\mathrm{H}_{2} \mathrm{O}_{2} / \mathrm{Fe}^{2+}\right)$, ultrasound (US) and wet air oxidation (WAO), while less conventional but evolving processes include ionizing radiation, microwaves, electron-beam irradiation, pulsed plasma and the ferrate reagent (Comninellis et al., 2008; Gültekin and Ince, 2007).

AOPs can be used either separately or in various combinations (e.g., $\mathrm{UV} / \mathrm{O}_{3}$, $\mathrm{O}_{3} / \mathrm{H}_{2} \mathrm{O}_{2}, \quad \mathrm{UV} / \mathrm{H}_{2} \mathrm{O}_{2}, \quad \mathrm{UV} / \mathrm{H}_{2} \mathrm{O}_{2} / \mathrm{O}_{3}, \quad \mathrm{TiO}_{2} / \mathrm{O}_{3}, \quad \mathrm{TiO}_{2} / \mathrm{H}_{2} \mathrm{O}_{2} / \mathrm{UV}, \mathrm{US} / \mathrm{H}_{2} \mathrm{O}_{2}, \quad$ US/Fenton, $\mathrm{US} / \mathrm{O}_{3}$, etc.). According to purposes, the role of chemical oxidation depends on the treatment objectives and may vary from partial remediation (removal of the more bioresistant fractions and their conversion to readily biodegradable intermediates that can subsequently be treated biologically) to complete mineralization of all pollutants to carbon dioxide, water and mineral salts (Mantzavinos and Psillakis, 2004; Huang et al., 1993). Therefore, AOPs have shown to be effective for the treatment of wastewaters, especially for the elimination of organic pollutants from industrial wastewaters (Badawy et al., 2006). Coupling AOP with a membrane-filtration step and/or biological posttreatment is conceptually beneficial as it can lead to increased overall treatment efficiencies compared with the efficiency of each individual stage. The rationale about preoxidation-membrane processes is that the partially oxidized effluent can pass through the selective membrane module, while large and less biodegradable molecules can be recycled back to the chemical oxidation reactor or be retained to undergo further chemical oxidation. In addition, preoxidation (e.g., ozone) is effective not only in maintaining stable membrane flux, but also in decreasing organic fouling of LPMs and biofouling of HPMs due to NOM and microorganism reduction. However, preoxidation may damage polymeric membranes incompatible with oxidants. The presence of inorganic metal species in the feedwater may also adversely influence the efficacy of preoxidation (Huang et al., 2009).

\subsubsection{Prefiltration and Biofiltration}

Basically, prefiltration involves the use of packed bed filters or other membranes as preliminary barriers to remove feedwater particles that are detrimental to the 
performance of the primary membrane filtration. In principle, the mechanism of the removal can be either physical sieving/straining or chemical adsorption/deposition (Huang et al., 2009). Granular media such as sand, garnet, diatom, GAC and anthracite can be utilized in prefiltration, targeting aquatic particles (greater than a few $\mu \mathrm{m}$ or smaller than $0.1 \mu \mathrm{m}$ ) that are relevant to water quality. Based on the type of filter media used, granular media filtration as pretreatment to membranes reduces biofouling, colloidal fouling and solids loading, and sometimes may require pretreatment (e.g., flocculation or preoxidation) to enhance the efficacy. For instance, the combination of sand filtration and LPMs has been successfully applied to purify biologically treated textile effluent in order to remove suspended solids, turbidity, color, and COD (chemical oxygen demand) (Capar et al., 2006). Generally, filters can be designed in three ways: single, dual and multimedia. The main advantage of conventional packed-bed filters employed in water and wastewater treatment is that their capacity can be effectively restored by hydraulic backwashing (O’Melia, 1980).

Biofiltration is distinguished from other biological treatments by the fact that there is a separation between the microorganisms and the treated waste. During biofiltration, the microbial biomass is immobilized to the bedding material, while the treated fluid flows through the filter. In such a system, the pollutants can be removed from feedwater by biological degradation associated with the attached microbial biomass, as well as adsorbed to the bedding material or to the microbial film (Cohen, 2001). Previous studies have been demonstrated that the use of feedwater pretreatment to prevent cell deposition and subsequent biogrowth would be more effective in the minimization of fouling than chemically cleaning after biofouling. In addition, biofiltration can also help in the minimization of fouling by removing easily and moderately biodegradable material. The removal of this material prior to the membrane may also help to reduce organic and biofouling through the reduction of nutrients. Besides commonly used biological activated carbon (BAC) and sand biofilters, there is evidence to suggest that iron oxide coated media biofilters could be a better choice for removal of NOM (Mosqueda-Jimenez and Huck, 2009; Wend et al., 2003; Speth et al., 1998).

In water reclamation, pretreatment has shifted from coagulation-sedimentationgranular media filtration towards LPM filtration. More or less, membrane prefiltration (e.g., MF, UF or MF + UF) has been considered as guarantee for a good and constant performance of NF and RO systems. Generally, MF has gained a wider acceptance for pretreatment because it not only can remove biomass flocs, individual bacterial cells and other particles carried over from the secondary clarifier, but also is economically more competitive than conventional methods. On the other hand, colloids, high MW SMP and EPS generated by microbial activity can be removed by UF, but the performance is highly dependent on the type of membrane material, the feed composition, the shape and the molecular weight cut-off (MWCO) of the membrane (Kim et al., 2008; Capar et al., 2006). 


\subsubsection{Ion Exchange}

Ion exchange is an important physico-chemical process and involves a chemical reaction and non-linear adsorption. Typical ion exchangers are ion exchange resins (functionalized porous or gel polymer), zeolites, montmorillonite, clay, and soil humus (Wikipedia, 2010). Ion exchangers are either cation exchangers that exchange positively charged ions (cations) or anion exchangers that exchange negatively charged ions (anions). In pretreatment systems, ion exchange resins are used in water softeners and organic scavengers (organic traps). Water softening uses a cation exchange resin to exchange principally calcium and magnesium ions for sodium ions, and thus, prevent the formation of calcium carbonate precipitates on $\mathrm{RO}$ membranes and other down stream processes. Organic scavengers utilize a macro-reticular anion exchange resin to remove a percentage of organic material from the feed water supply. As the feed water passes down through the bed of anion resins in the chloride form the negatively charged organics are preferentially absorbed onto the positively charged active sites on the resin beads to displace the chloride ions. The large molecules also get trapped in pores in the resin beads and are removed by a size exclusion process (Bennett, 2007).

Interest in the ion exchange process application in water treatment increased when the new Magnetic Ion Exchange resin, MIEX ${ }^{\circledR}$ was developed. The MIEX ${ }^{\circledR}$ resin was developed by Orica, Australian, and optimized for the removal of negatively charged organic particles from water. MIEX $^{\circledR}$ resin is micro-sized, macroporous, and strong base ion exchange resin made from a moderately cross-linked acrylic skeleton. MIEX $^{\circledR}$ has been demonstrated to remove varying levels of dissolved organic matter, inorganic anions such as nitrate and sulphate and micropollutants including non-ionic pesticides. The resin is especially effective in separating the low MW organic particles. The removal efficiency can also be influenced by temperature, $\mathrm{pH}$ and the presence of other anions. Since MIEX ${ }^{\circledR}$ does not remove turbidity and even may generate secondary pollution because the small part of the resin might be carried away from the system, the most likely application of MIEX $^{\circledR}$ within international development is as pretreatment before disinfection or membrane filtration (Neale and Schäfer, 2009; KabschKorbutowicz et al., 2006). Particularly, MIEX ${ }^{\circledR}$ combined with LPMs can minimize the secondary pollution caused by resin carried away from the system and eliminates the losses of resin. When MIEX ${ }^{\circledR}$ combined with UF, the efficiency of the integrated process exhibited high retention of NOM $(95.5 \%)$ even for very small resin doses $(10 \mathrm{~mL} / \mathrm{L})$ and high UF MWCO (30 kDa) (Kabsch-Korbutowicz et al., 2008).

\subsection{Fouling Control for Low Pressure Membrane (LPM) Processes}

In LPM processes for water and wastewater treatment, the impacts of pretreatment on MF and UF membranes have focused on either rejection of targeted 
pollutants or mitigation of membrane fouling. Since LPM processes are extremely flexible, they can be used in conjunction with different pretreatments to achieve superior treatment results rather than by membrane alone. $\mathrm{CF}$, adsorption and preoxidation are widely used pretreatment unit processes for LPM applications in surface water treatment, municipal wastewater treatment and industrial wastewater treatment.

\subsubsection{Fouling Control in Surface Water Treatment}

The variation of surface water quality depends on hydrodynamic, chemical, biological and meteorological mechanisms, together with other negative impacts caused by important procedures such as eutrophication, the input of hygienic relevant microorganisms or persistent organic pollutants by treated wastewater. The conventional treatment for surface water such as $\mathrm{CF}$, sedimentation and filtration has been applied in producing drinking water for many years. Nowadays, due to new developments in technology and research, it is possible to assess the water treatment processes more effectively with regard to current and future requirements (Panglisch et al., 2010). Hence, basic requirements are:

- particle removal

- $\quad$ removal of microorganisms (e.g., algae, viruses, bacteria);

- removal of manganese;

- $\quad$ reduction of organic pollutants (especially NOM);

- reduction of color;

- reduction of re-growth potential.

Khan et al. (2007) investigated settled river water treatment by a biofiltrationPAC-MF hybrid system. Biofiltration played a significant role in removing bulk solution carbohydrates. The use of a high dose of PAC $(40 \mathrm{~g} / \mathrm{L})$ inside a submerged MF unit further resulted in improved performance and a lower carbohydrate and protein concentration on the membrane and in the bulk fluid. Overall, the use of biofiltration of feedwater and high-dose PAC showed promise for improved performance of the membrane system. Chae et al. (2008) studied fouling control of two pilot-scale polyvinylidene fluoride (PVDF) MF membranes (symmetric and composite) with CF (PACl as flocculant), sedimentation and sand filtration (SF) pretreatment to produce potable water from river water. Pre-chlorination before MF and post-chlorination after MF were also compared in terms of operating period. It was found that most of turbidity, humic substances, organic matter, Al and Fe were effectively removed by coagulation, sedimentation and SF pretreatment. The pre-chlorination adversely affected membrane fouling due to oxidization and deposition of inorganic substances. However, the postchlorination by $\mathrm{NaOCl}$ effectively extended the operating period of the two membranes. The composite membrane was more resistant to membrane fouling than the symmetric membrane though the nominal pore size of the former $(0.02 \mu \mathrm{m})$ was smaller than that of the latter $(0.1 \mu \mathrm{m})$, because the formation of a dense cake layer on the top of the 
composite membrane provided benefits in terms of both pollutant removal and fouling mitigation. Table 19.3 summarizes some recent research works on fouling control of pretreatment-LPM processes in surface treatment.

The potential of AOPs has gained a great deal of research interest over the last decade after the discovery of photovoltaic property of nano-structured titanium dioxide $\left(\mathrm{TiO}_{2}\right)$ and the applications of the hybrid photocatalytic membrane reactors (PMRs) in water and wastewater treatment. The PMRs can be divided into two main groups: (a) reactors with $\mathrm{TiO}_{2}$ suspended in the reaction mixture and (b) reactors with $\mathrm{TiO}_{2}$ fixed on a carrier material (e.g., glass, quartz, stainless steel, pumice stone, titanium metal, zeolites, etc.). In PMRs, photocatalytic degradation reactions and $\mathrm{TiO}_{2}$ separation are achieved simultaneously through membrane separation (Mozia, 2010). Thus, PMRs have some advantages compared to conventional photoreactions:

(1) confining of the photocatalyst in the reaction environment by means of the membrane;

(2) control of a residence time of molecules in the reactor;

(3) realization of a continuous process with simultaneous catalyst and products separation from the reaction environment;

(4) avoiding some additional operations and reusing of the photocatalyst in further runs, which is practically impossible when the conventional separation system such as CF-sedimentation is applied; energy saving and reducing the size of installation.

Although the membrane fouling due to $\mathrm{TiO}_{2}$ nanoparticles can be avoided in PMRs with photocatalytic membranes, the efficiency of photo-degradation is lower than that with the photocatalyst in suspension because of the instability of coated photocatalyst layers. Another drawback is that it is not possible to adjust the catalyst loading to the composition of the treated solution. Therefore, photocatalytic slurry-type membrane reactors have been considered as an effective technique due to their substantially higher catalyst surface areas and lower susceptibility to surface deactivation effects. Photocatalytic slurry-type membrane reactors can be designed with either crossflow or submerged membrane modules (Figure 19.1). However, the application of submerged membranes might overcome or reduce the unfavorable phenomenon of membrane fouling by $\mathrm{TiO}_{2}$ nanoparticles. Most of the PMRs combine photocatalysis with pressure driven membrane processes such as MF, UF and NF. Recently new types of PMRs have also studied with respect to photocatalysis with dialysis, pervaporation (PV), and direct contact membrane distillation (DCMD, MD). The main advantage of these configurations is that the presence of a photocatalyst does not cause the membrane fouling (Mozia, 2010; Ryu et al., 2005). 
Table 19.3 Fouling control of pretreatment-LPM processes in surface water treatment.

\begin{tabular}{|c|c|c|c|c|}
\hline Raw water & Pretreatment & Membrane & Results of fouling control & References \\
\hline $\begin{array}{l}\text { Water from } \\
\text { reservoir, } \\
\text { Australia }\end{array}$ & $\begin{array}{l}\text { MIEX }^{\circledR}-\mathrm{CF} ; \mathrm{MIEX}^{\circledR}-\mathrm{PAC} ; \\
\mathrm{MIEX}^{\circledR}-\mathrm{PAC}-\mathrm{CF}\left(\mathrm{MIEX}^{\circledR}: 10\right. \\
\mathrm{mL} / \mathrm{L} \text { at } \mathrm{pH}=6.2, \text { Alum } 40 \\
\mathrm{mg} / \mathrm{L} \text { and } \mathrm{PAC} 40 \mathrm{mg} / \mathrm{L})\end{array}$ & $\begin{array}{l}\text { Submerged } \\
\text { hydrophilic flat } \\
\text { sheet PVDF MF } \\
\text { (pore size } 0.22 \mu \mathrm{m} \text { ) }\end{array}$ & $\begin{array}{l}\text { - } \text { MIEX }^{\circledR}-C F \text { and MIEX } \\
\text { majority of bulk water DOC of all MW ranges, } \\
\text { including very high MW colloidal (> } 50000 \mathrm{Da}) \text {, and } \\
\text { successfully prevented short-term fouling of MF. } \\
\text { - } \text { MIEX }^{\circledR}-\mathrm{PAC} \text { did not remove the colloidal } \\
\text { components and were unable to prevent fouling. }\end{array}$ & $\begin{array}{l}\text { Fabris et al., } \\
2007\end{array}$ \\
\hline $\begin{array}{l}\text { River water, } \\
\text { Korea }\end{array}$ & Ozone & $\begin{array}{l}\text { Submerged hollow } \\
\text { fiber PTFE MF } \\
\text { (pore size } 0.45 \mu \mathrm{m} \text { ) }\end{array}$ & $\begin{array}{l}\text { - Ozone destruction prevented foulant (mainly } \\
\text { pharmaceuticals) accumulation on MF. } \\
\text { - Ozone pretreatment effectively suppressed TMP } \\
\text { development and yielded a two-fold lower TMP } \\
\text { value compared to that in MF process alone. }\end{array}$ & Oh et al, 2007 \\
\hline $\begin{array}{l}\text { River water, } \\
\text { Korea }\end{array}$ & $\begin{array}{l}\text { PAC-CF (PACl as flocculant) } \\
\text { due to the substantial variation } \\
\text { of raw water qualities (high } \\
\text { turbidity and high algae counts } \\
\text { with fluctuated temperature) }\end{array}$ & $\begin{array}{l}\text { Submerged hollow } \\
\text { fiber PVDF UF } \\
\text { (pore size } 0.04 \mu \mathrm{m})\end{array}$ & $\begin{array}{l}\text { - The CF pretreatment was very effective in reducing } \\
\text { membrane fouling caused by high turbidity. } \\
\text { - The addition of PAC relieved the aggravation of } \\
\text { fouling by the removal of DOC and trihalomethane } \\
\text { formation potential. However, the PAC addition } \\
\text { could not stop the undergoing fouling. }\end{array}$ & $\begin{array}{l}\text { Kweon et al., } \\
2009\end{array}$ \\
\hline $\begin{array}{l}\text { Lake water, } \\
\text { Japan }\end{array}$ & $\begin{array}{l}\text { Super PAC (SPAC); } \\
\text { SPAC-CF }\end{array}$ & $\begin{array}{l}\text { Crossflow tubular } \\
\text { ceramic MF (pore } \\
\text { size } 0.1 \mu \mathrm{m} \text { ) }\end{array}$ & $\begin{array}{l}\text { - SPAC led to less TMP increase and more stable flux } \\
\text { than PAC alone. } \\
\text { - Larger and more porous floc particles resulted in } \\
\text { forming more permeable cake layer during SPAC- } \\
\text { CF pretreatment when compared to flocs formed } \\
\text { during PAC-CF or CF alone. } \\
\text { - Both reversible and irreversible fouling was reduced } \\
\text { due to better NOM removal. }\end{array}$ & $\begin{array}{l}\text { Matsui et al., } \\
2009\end{array}$ \\
\hline $\begin{array}{l}\text { Untreated } \\
\text { surface water, } \\
\text { The } \\
\text { Netherlands }\end{array}$ & $\begin{array}{l}\text { Fluidized ion exchange (FIX) } \\
\text { with cation and anion } \\
\text { exchange resins }\end{array}$ & $\begin{array}{l}\text { Crossflow hollow } \\
\text { fiber PES/PVP UF } \\
\text { (MWCO } 100 \mathrm{kDa})\end{array}$ & $\begin{array}{l}\text { - FIX removed } 60 \% \text { NOM despite high loads of SS. } \\
\text { - Reversible fouling increased after cation FIX } \\
\text { treatment due to more open NOM fouling layers on } \\
\text { UF membrane, while irreversible fouling decreased } \\
\text { after cation FIX treatment due to less calcium-NOM } \\
\text { complex formation. }\end{array}$ & $\begin{array}{l}\text { Cornelissen et } \\
\text { al., } 2009\end{array}$ \\
\hline
\end{tabular}




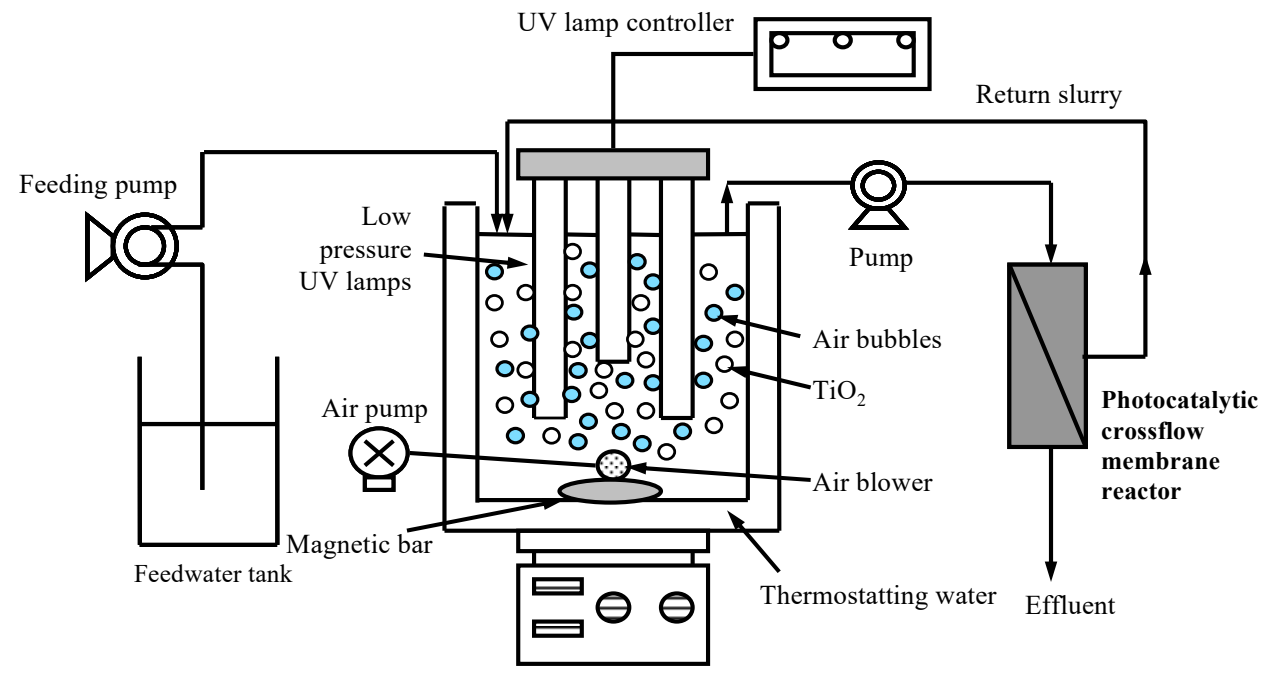

(a) Crossflow mode PMR

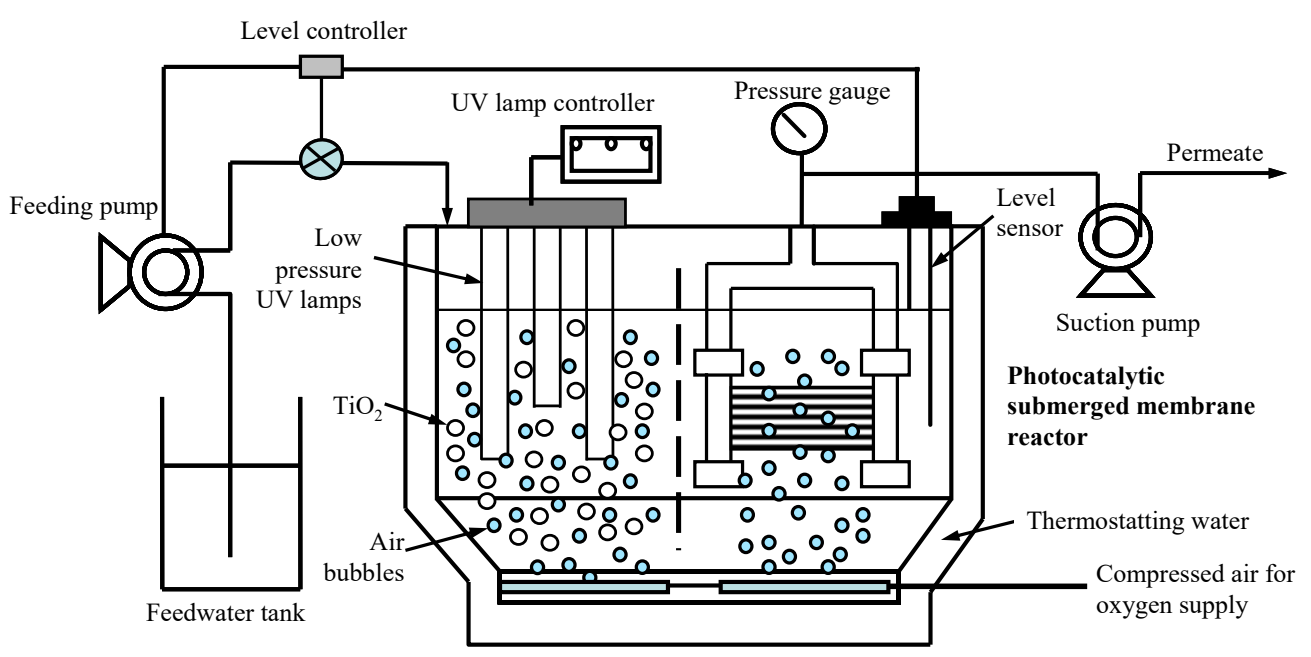

(a) Submerged mode PMR

Figure 19.1 The diagram of PMRs with crossflow and submerged membrane modules.

Ryu et al. (2005) developed and tested a pilot-scale submerged PMR for controlling micropollutants in water. The membrane was a $0.1 \mu \mathrm{m}$ hollow fiber MF module with an effective surface area of $8 \mathrm{~m}^{2} . \mathrm{TiO}_{2}$ (Degussa P25) was selected with an average surface area of $50 \mathrm{~m}^{2} / \mathrm{g}$. In a continuous suction mode, the formation of $\mathrm{TiO}_{2}$ cake layers on the membrane surface occurred and caused a substantial increase in TMP. However, no further fouling or TMP build-up took place with an intermittent suction mode with the 9-min suction and 3-min pause period. However, high alkalinity and 
hardness in water may deteriorate the performance of PMRs in inhibiting the reaction rate by deactivating the catalyst and scavenging hydroxyls thereby fouling the membrane by scaling (Huang et al., 2007). Huang et al. (2008) investigated a crossflow PMR in drinking water treatment. The application of the $\mathrm{TiO}_{2} / \mathrm{UV}$ process as $\mathrm{MF}$ (PVDF, $0.2 \mu \mathrm{m}$ ) or UF (cellulose acetate, MWCO $100 \mathrm{kDa}$ ) pretreatment was proved to be very effective in controlling membrane fouling by NOM, even though the rate of total organic carbon (TOC) removal was relatively low. At the $\mathrm{TiO}_{2}$ concentration of $0.5 \mathrm{~g} / \mathrm{L}$, fouling of both MF and UF was completely eliminated after $20 \mathrm{~min}$ of treatment. The effectiveness in membrane fouling control is the result of the changes in NOM molecular characteristics due to the preferential removal and transformation of high $\mathrm{MW}$, hydrophobic NOM compounds.

To alleviate membrane fouling by $\mathrm{TiO}_{2}$ nano-structured particles, onedimensional (1-D) nanostructured $\mathrm{TiO}_{2}$ including nanowires, nanofibers, nanorods and nanotubes, have become more popular due to their superior properties relative to conventional bulk materials. These 1-D $\mathrm{TiO}_{2}$ materials are more easily separated and recovered than $\mathrm{TiO}_{2}$ nanoparticles because of longer length in the size of micrometer. In addition, the 1-D $\mathrm{TiO}_{2}$ materials still possess the properties of nanomaterials including high surface area and nanosize effect because they are nanosized in their diameter. Zhang et al. (2009) proposed two different diameter 1-D TiO 2 nanowires $\left(10 \mathrm{~nm} \mathrm{TNW}_{10}\right.$ and 20-100 $\mathrm{nm} \mathrm{TNW} 20$ ) for the degradation of humic acid, followed by MF. The results showed that $\mathrm{TNW}_{10}$ and $\mathrm{TNW}_{20}$ could be totally separated and recovered by $0.2 \mu \mathrm{m} \mathrm{MF}$. The membrane fouling caused by $\mathrm{TNW}_{10}$ and $\mathrm{TNW}_{20}$ was much less than that of $\mathrm{P} 25$ due to the formation of more porous cake and less pore plugging.

Overall, surface water pretreatment prior to membrane filtration can be done either by adjusting fouling cake layer porosity, increasing frequency of particle-particle collisions or reducing the NOM/DOC concentration.

\subsubsection{Fouling Control in Wastewater Treatment}

Most studies of pretreatment-LPM processes in municipal wastewater treatment have been focused on tertiary treatment of the secondary effluent for water reclamation and reuse. Lee et al. (2007) evaluated the factors affecting pretreatment conditions for hybrid UF membrane processes in secondary effluent reuse. They mentioned that particle sizes ranging between 0.2 and $1.2 \mathrm{~mm}$ caused a significant impact on membrane fouling in all cases even with or without a CF process. As pretreatment of the UF membrane process, the CF (alum dose of $50 \mathrm{mg} / \mathrm{L}$ ) significantly improved the permeate flux. Goren et al. (2008) tested CF and PAC as pretreatment to three polysulfone (PS, MWCO: 20, 50 and $100 \mathrm{kDa}$ ) and two polyethersulphone (PES, MWCO: 2 and $10 \mathrm{kDa}$ ) UF membranes during tertiary treatment of the secondary effluent from municipal WWTP in Israel. They found that the sequence of CF and adsorption didn't affect TOC 
removal. With optimal ferric chloride $(130 \mathrm{mg} / \mathrm{L})$ and PAC $(0.6 \mathrm{~g} / \mathrm{L})$ doses and PS-50 membrane, CF-PAC pretreatment minimized the flux drop (in the low range of $\sim 3 \%$ ) and gave an average $97 \%$ reduction in organic molecules with molecular weight $<800$ Da (effluent TOC $<3 \mathrm{mg} / \mathrm{L}$ ).

Guo et al. (2005b) conducted a study aiming at identifying the effect of pretreatment such as $\mathrm{CF}$ ( $\mathrm{FeCl}_{3}$ as flocculant) and/or PAC adsorption on critical flux of crossflow MF (PVDF, $0.45 \mu \mathrm{m}$ ) in treating synthetic biologically treated sewage effluent (BTSE). The results indicated that: (a) $\mathrm{CF}$ alone as a pretreatment could effectively remove the large molecular weight organic matter from 30 to $60 \mathrm{kDa}$; (b) $\mathrm{CF}$ together with adsorption as a pretreatment to CFMF, could remove both large and small molecular weight organics; (c) $\mathrm{CF}$ as a pretreatment was significantly better than adsorption in improving the critical flux; and (d) critical flux increased from $100 \mathrm{~L} / \mathrm{m}^{2} \cdot \mathrm{h}$ to $520 \mathrm{~L} / \mathrm{m}^{2} \cdot \mathrm{h}$ when $\mathrm{CF}$-adsorption was applied. They also investigated in-line $\mathrm{CF}$ and PAC adsorption as pretreatment to reduce fouling of a submerged hollow fiber microfiltration (SMF, polyethylene, $0.1 \mu \mathrm{m}$ ) in treating the same BTSE (Guo et al., 2010). The SMF system was operated at a very high filtration rate at $60 \mathrm{~L} / \mathrm{m}^{2} \cdot \mathrm{h}$. A spiral flocculator (SF) composed of rapid mixing and slow mixing device was used. In SFPAC-SMF experiment, a predetermined low dose of PAC (12 $\mathrm{g}$ in total) was added into the membrane tank. Pre-CF coupled with SMF exhibited higher organic removal than SMF alone. After SF pretreatment, the removal efficiency increased nearly from 44 to $71 \%$. In conjunction with PAC adsorption, the removal of organic pollutants increased up to $96 \%$, which indicated that the SF-PAC-SMF could successfully remove the major refractory organics present in the wastewater. The TMP development of SMF alone was higher than those with pretreatment. Within the operation period, the TMP reached up to $50 \mathrm{kPa}$; the membrane was backwashed 7 times, which indicated an irreversible fouling phenomenon had occurred. With pretreatment, the TMP development only increased marginally during the 8 hours of high rate filtration (e.g., $2.5 \mathrm{kPa}$ and $0.8 \mathrm{kPa}$ increase for SF-SMF and SF-PAC-SMF, respectively). Thus, the CF is very helpful in reducing the membrane fouling, resulting in stable membrane productivity.

Fan et al. (2008) also conducted research on fouling in LPM filtration of activated sludge-lagoon effluent by investigating prefiltration, $\mathrm{CF}$ and anion exchange resin as pretreatments for reducing fouling of MF (PVDF, $0.22 \mu \mathrm{m}$ ) and UF (PES, 100 $\mathrm{kDa})$ membranes. Prefiltration using $1.5 \mu \mathrm{m}$ glass-fibre filters enhanced the permeate flux for MF by removing particulates, but had little effect for UF. Settling after CF had only minimal effect on MF and UF performance compared with in-line CF. Alum performed better than ferric chloride for flux improvement, and increasing flocculant dosage resulted in an increase in flux rate. Although marked flux improvement was obtained by CF pretreatment even at a low dosage $\left(2 \mathrm{mg} / \mathrm{L} \mathrm{Al}^{3+}\right.$ or $\left.\mathrm{Fe}^{3+}\right)$ due to internal membrane fouling being substantially alleviated, $5 \mathrm{mg} / \mathrm{L}$ of $\mathrm{Al}^{3+}$ was very effective for maintaining higher flux and mitigating internal membrane fouling. The better performance of alum treatment was attributed to the more open porous structure of the 
alum-organic floc layer on the membrane surface compared with the gel-like and denser foulant layer for the feed treated with ferric chloride. Anion exchange resin removed $>$ $50 \%$ of effluent organic matter $(\mathrm{EfOM})$ at a resin dosage of $10 \mathrm{~mL} / \mathrm{L}$, but did not improve the flux or reduce irreversible membrane fouling. Detailed organic compositional analyses showed that the very high-molecular weight organic materials (40-70 kDa) comprised of hydrophilic components such as soluble microbial products, and protein-like extracellular matter were the major cause of membrane fouling.

Baek and Chang (2009) studied the effect of CF with alum and ferric sulfate as well as activated carbon $(850-140 \mathrm{~mm})$ on membrane fouling using two different hydrophobicity UF membranes (YM30 and PM30) prior to direct membrane filtration of secondary effluent. $R_{c}$ is the cake resistance formed by the cake layer deposited over the membrane surface, and the fouling resistance, $\mathrm{R}_{\mathrm{f}}$, is the resistance caused by solute adsorption into the membrane pores and walls. Optimum $\mathrm{pH}$ and dose were found to be 8 and $50 \mathrm{mg} / \mathrm{L}$ for alum, 7 and $10 \mathrm{mg} / \mathrm{L}$ for ferric sulfate, and 8 and $500 \mathrm{mg} / \mathrm{L}$ for activated carbon adsorption. Membrane filterability was enhanced by the pretreatment using flocculating agents with both decreased $\mathrm{R}_{\mathrm{c}}$ and $\mathrm{R}_{\mathrm{f}}$. Colloidal particles which are mainly responsible for membrane fouling were coagulated and removed. Flux enhancement of the hydrophobic membrane (PM30) by CF was always greater than that of the hydrophilic membrane (YM30). Thereby, for the purpose of membrane fouling control, pretreatment using CF could be more beneficial for hydrophobic membranes than for hydrophilic membranes. Unlike the pretreatment using flocculants, carbon adsorption did not reduce $\mathrm{R}_{\mathrm{c}}$, but decreased $\mathrm{R}_{\mathrm{f}}$ instead because activated carbon could remove soluble foulants rather than particulates.

The Fenton oxidation process as pretreatment to LPMs has the advantages of both oxidation and coagulation in which ferrous and ferric ions also work as flocculants leading to a dual stage organic removal resulting in lower toxicity, COD and color level. Chiu and James (2006) employed the Fenton process to enhance the sustainable flux in treating synthetic secondary effluent using non-circular tubular ceramic MF (pore size of $0.2 \mu \mathrm{m})$. They compared the efficiencies of the Fenton-oxidation coagulation process (FOC, using varying amounts of $\mathrm{Fe}^{2+}$ and a fixed quantity of $\mathrm{H}_{2} \mathrm{O}_{2}$ ), Fenton-oxidation oxidation process (FOO, a constant amount of $\mathrm{Fe}^{2+}$ but varying quantities of $\mathrm{H}_{2} \mathrm{O}_{2}$ ), and processes involving only oxidation or only coagulation as pretreatment to MF. Higher sustainable fluxes were found in all pre-treated feeds regardless of the pre-treatment options. The trend in TOC removal was FOC $>$ coagulation $>$ FOO $>$ oxidation. The trend in the sustainable fluxes was the same as for TOC with FOC achieving the best flux enhancements of up to $416 \%$ and oxidation being least effective (up to $47.7 \%$ ). The fluxes achieved with FOC were mainly attributed to the effective removal of organics and to a lesser extent an increase in average particle size. Table 19.4 gives other representative examples of pretreatment-LPM hybrid systems for secondary effluent polishing. 
Table 19.4 Fouling control of pretreatment-LPM processes in municipal wastewater treatment and secondary effluent polishing.

\begin{tabular}{|c|c|c|c|c|}
\hline Raw water & Pretreatment & Membrane & Results of fouling control & References \\
\hline $\begin{array}{l}\text { Fresh sewage } \\
\text { from municipal } \\
\text { WWTP, Korea }\end{array}$ & $\begin{array}{l}\text { Electric fields } \\
\text { treatment }+\mathrm{CF} \\
\text { (PACl as } \\
\text { flocculant) }\end{array}$ & $\begin{array}{l}\text { Submerged } \\
\text { inorganic tubular } \\
\text { MF (pore size } 1 \\
\mu \mathrm{m})\end{array}$ & $\begin{array}{l}\text { Electric fields treatment prior to MF enhanced permeate flux. } \\
\text { Thus, it can be utilized for membrane biofouling reduction, } \\
\text { microbial inactivation and the enhancement of particle } \\
\text { coagulation. } \\
\text { - CF dosage could be saved about } 75 \% \text { compared with non- } \\
\text { electric fields for achieving } 95 \% \text { turbidity removal at } 10 \\
\mathrm{kV} / \mathrm{cm} \text {. }\end{array}$ & $\begin{array}{l}\text { Kim et al., } \\
2007\end{array}$ \\
\hline $\begin{array}{l}\text { Biologically } \\
\text { treated } \\
\text { unchlorinated } \\
\text { effluent from } \\
\text { municipal } \\
\text { WWTP, Greece }\end{array}$ & $\begin{array}{l}\text { In-line CF (Alum } \\
\text { as flocculant); PAC } \\
\text { or GAC }\end{array}$ & $\begin{array}{l}\text { Submerged } \\
\text { hollow fiber UF } \\
\text { (Zenon ZeeWeed- } \\
\text { 10) }\end{array}$ & $\begin{array}{l}\text { - In-line CF only removed the fraction of colloidal organic } \\
\text { matter with size over } 0.04 \mu \mathrm{m} \text { without removing DOC to a } \\
\text { substantial extent. Thus, didn't improve the performance of } \\
\text { UF. } \\
\text { - After PAC addition, TMP increased rapidly due to the } \\
\text { formation of PAC cake on membrane surface. However, } \\
\text { addition of GAC resulted in efficient removal of DOC and } \\
\text { metals without causing an increase to TMP. }\end{array}$ & $\begin{array}{l}\text { Dialynas and } \\
\text { Diama- } \\
\text { dopoulos, } \\
2008\end{array}$ \\
\hline $\begin{array}{l}\text { Secondary } \\
\text { effluent from } \\
\text { WWTP, USA }\end{array}$ & $\begin{array}{l}\text { Pre-ozonation }+\mathrm{CF} \\
\text { (PACl as } \\
\text { flocculant) }\end{array}$ & $\begin{array}{l}\text { Dead-end } \\
\text { METAWATER } \\
\text { ceramic } \\
\text { membrane } \\
\text { element (pore size } \\
0.1 \mu \mathrm{m} \text { ) }\end{array}$ & $\begin{array}{l}\text { - The ceramic membrane demonstrated stable performance } \\
\text { (over a 4-week period) at a filtration flux of } 170 \mathrm{~L} / \mathrm{m}^{2}-\mathrm{h} \text { with } \\
\text { pretreatment using PACl }(1 \mathrm{mg} / \mathrm{L} \text { as } \mathrm{Al}) \text { and ozone }(4 \mathrm{mg} / \mathrm{L}) \text {. } \\
\text { - Ozone pretreatment is effective at degrading colloidal NOM } \\
\text { responding for the majority of fouling. } \\
\text { - PACl helps to destabilize the micro-particles in the water and } \\
\text { promote the aggregation of NOM inside of the flow channels } \\
\text { that can be effectively removed by high pressure backwash. }\end{array}$ & $\begin{array}{l}\text { Lehman and } \\
\text { Liu, } 2009\end{array}$ \\
\hline $\begin{array}{l}\text { Biologically } \\
\text { advanced treated } \\
\text { secondary } \\
\text { effluent from } \\
\text { WWTP, Korea }\end{array}$ & $\begin{array}{l}\mathrm{CF} \text { (PACl as } \\
\text { flocculant); } \\
\text { Ozonation }\end{array}$ & $\begin{array}{l}\text { Dead-end PVDF } \\
\text { MF (pore size } \\
0.22 \mu \mathrm{m})\end{array}$ & $\begin{array}{l}\text { - CF pretreatment resulted in efficient COD and phosphorus } \\
\text { removal at dose above } 30 \mathrm{mg} / \mathrm{L} \text {, while more than } 90 \% \text { of the } \\
\text { color was removed even at a low dosage of ozone }(5 \mathrm{mg} / \mathrm{L}) \text {. } \\
\text { - Employing PACl coagulation and ozonation as a pretreatment, } \\
\text { the extent of flux decline rates were enhanced up to } 88 \text { and } \\
38 \% \text {, respectively. }\end{array}$ & $\begin{array}{l}\text { Park et al., } \\
2010\end{array}$ \\
\hline
\end{tabular}


Besides municipal wastewater treatment, pretreatment-LPM hybrid systems have been investigated in decolorizing wastewaters. The underlying motivation behind studying colored wastewater treatment by membrane processes is that the removal of dyes from the wastewater by other conventional processes has caused problems in sewage treatment or been proven difficult due to their relative non-biodegradability (Mutlu et al., 2002). Al-Bastaki and Banat (2004) proposed a bentonite adsorption -UF hybrid system to overcome the bed clogging problem of the commercial packed-bed column adsorbers because of insoluble solids in textile effluent streams, as well as to remove color caused by methylene blue (MB) dye. Permeate flux increased linearly with increasing pressure while the permeate concentration remained almost constant. The addition of bentonite significantly increased the rejection coefficient of MB but decreased the permeate flux. However, membrane fouling was reduced in the presence of bentonite compared to UF alone. A bentonite concentration of $600 \mathrm{mg} / \mathrm{L}$ was sufficient to achieve $97 \%$ dye rejection. Utilizing this system allowed the dissolved organics and insoluble filterable solids to be removed in one-step, and the treated water to either be recycled in the process or reused for other purposes.

Lee et al. (2006) evaluated the performance of alum CF-sedimentation-PAC adsorption as pretreatment to submerged hollow fiber MF in treating two kinds of reactive dyes (Orange 16 and Black 5). MF alone was not effective in the retention of dyes. When dye wastewater alone was fed into the system without CF or adsorption pretreatment, membrane fouling was severe with almost $50 \%$ flux decline of the initial permeate flux within $5 \mathrm{~h}$ of operation. This was mainly due to the deposition of reactive dyes on membrane surface, including adsorption, pore blocking, precipitation and cake formation. On the other hand, with CF and adsorption pretreatment the MF performance was very stable, and the fluxes remained nearly constant at an initial level of approximately 330 and $324 \mathrm{~L} / \mathrm{m}^{2} \cdot \mathrm{h}$ for Black 5 and Orange 16 for the entire $5 \mathrm{~h}$ of experimental run. The reason for reduced fouling was due to the activated carbon adsorption of reactive dyes. The combined process achieved complete decolorization $(99.9 \%)$ of both reactive dyes from synthetic wastewater. Jirankova et al. (2007) also stated that activated carbons possess perfect adsorption ability for relatively low MW organic compounds. When combining PAC with the dead-end polypropylene hollow fiber MF membrane to treat wastewater containing reactive dyes, PAC formed quite loosely cake adhered to the membrane, and PAC tendency for irreversible fouling was extremely low. Membrane backwash was effective in restoring the permeate flux (or pressure difference) back to the initial values.

The effect of ozonation followed by biological activated carbon (BAC) filtration and PVDF UF (MWCO: $100 \mathrm{kDa}$ ) performance of a highly colored activated sludge effluent was investigated (Nguyen and Roddick, 2010). Ozonation at a dose of $10 \mathrm{mg} / \mathrm{L}$ reduced the true color of the raw activated sludge effluent by $74 \%$. Meanwhile, BAC filtration removed some of the very hydrophobic acid and hydrophilic charged fractions from the ozonated activated sludge effluent, and lowered the turbidity to $<1.0 \mathrm{NTU}$. The 
major dissolved organic foulants of the UF membrane from the raw activated sludge effluent were polysaccharides, proteins, polysaccharide-like and protein-like materials, and humic substances. Although ozonation and BAC filtration did not change the identity of the predominant membrane foulants, fouling of the UF membrane was reduced after ozonation due to partial oxidation of the membrane foulants to low molecular weight acids and low molecular weight neutrals, some of which were then utilized by the microorganisms in the BAC filtration process. Afterwards, BAC filtration further improved the UF flux, mainly by lowering the suspended solids level of the ozonated activated sludge effluent. The hydraulically irreversible fouling of the UF membrane was reduced after ozonation while BAC filtration did not cause a further decrease in this type of fouling. Apart from decolorizing wastewaters, Table 19.5 also lists some other applications of pretreatment-LPM hybrid systems in industrial wastewater treatment.

\subsubsection{Fouling Control in MBR Processes}

Although the MBR offers the effective separation of pollutants and persistence to high or shock loadings in wastewater treatment and reuse, membrane fouling is still an unavoidable obstacle to further development and commercialization of the MBR processes (Guo et al., 2008). Generally, intermittent suction, backwashing, module design improvement and optimization aeration can help to minimize MBR fouling. A number of explored technologies such as chemical precipitation-MBR (Kornboonraksa et al., 2009) and preoxidation-MBR (Feng et al., 2010) hybrid systems have also been used in attempts to overcome membrane fouling and enhance biodegradability in MBR processes. However, due to the complex characteristics of the mixed liquor, various trials have been carried out to minimizing membrane fouling by either adopting adsorbents or flocculants, particularly for the submerged MBR (SMBR) configuration which can assist in significantly reducing power consumption. Since adsorbents have dual functions of adsorption and supporting attached growth, the details will be given in Chapter 20. In this chapter, we focus on discussing MBR fouling control with addition of flocculants.

The flocculants used in the flocculation process for the water and wastewater treatment, can be classified into three groups: (a) inorganic flocculants; (b) organic synthetic polymer flocculants; and (c) naturally occurring bio-polymer flocculants (Xing et al., 2010; Shih et al., 2001). Inorganic flocculants such as $\mathrm{FeCl}_{3}$ and alum are the most common flocculants used in water and wastewater treatment. They have been reported effectively enhancing filterability of mixed liquor and controlling membrane fouling by supplying positive charges for soluble macromolecular substances and sludge flocs, and enhancing the function of charge neutralization. 
Table 19.5 Fouling control of pretreatment-LPM processes in industrial wastewater treatment

\begin{tabular}{|c|c|c|c|c|}
\hline Raw water & Pretreatment & Membrane & Results of fouling control & References \\
\hline $\begin{array}{l}\text { Phosphorus- } \\
\text { containing } \\
\text { wastewater from } \\
\text { an automobile } \\
\text { plant, China }\end{array}$ & Lime softening & $\begin{array}{l}\text { Crossflow } \\
\text { symmetric } \\
\text { microporous } \\
\mathrm{Al}_{2} \mathrm{O}_{3} \text { ceramic } \\
\mathrm{MF}(\text { pore size } \\
0.2 \mu \mathrm{m})\end{array}$ & $\begin{array}{l}\text { - At the lime dosage of } 680 \mathrm{mg} / \mathrm{L} \text {, phosphate removal increased } \\
\text { from } 11 \% \text { (without pretreatment) to } 99.7 \% \text {, and the permeate flux } \\
\text { was about } 60 \% \text { greater than that when lime was not used. } \\
\text { Pretreatment increased particle size, which mitigated membrane } \\
\text { fouling by reducing the extent of pore plugging and forming a } \\
\text { more porous cake on the membrane surface. }\end{array}$ & $\begin{array}{l}\text { Zhang et al., } \\
2006\end{array}$ \\
\hline $\begin{array}{l}\text { High strength } \\
\text { wastewater from } \\
\text { the anaerobic } \\
\text { digestion of } \\
\text { municipal solid } \\
\text { wastes with high } \\
\mathrm{N} \text { and } \mathrm{P}, \text { Canada }\end{array}$ & $\begin{array}{l}\mathrm{CF} \text { (Alum as } \\
\text { flocculant) }\end{array}$ & $\begin{array}{l}\text { Submerged } \\
\text { hollow fiber UF } \\
\text { (pore size } 0.04 \\
\mu \mathrm{m})\end{array}$ & $\begin{array}{l}\text { The lowest average fouling rate }(<1 \mathrm{KPa} / \mathrm{min}) \text { occurred at } \mathrm{pH} 5.5 \\
\text { and alum dosages ranging from } 700 \text { to } 1200 \mathrm{mg} / \mathrm{L} \text {. } \\
\text { - } \mathrm{CF} \text { pretreatment greatly reduced the membrane fouling rates due } \\
\text { to the increased particle sizes and decreased concentration of } \\
\text { foulants. A better filterability was confirmed for the particles } \\
\text { formed from sweep coagulation than those from charge } \\
\text { neutralization. In general, the permeate flux increased with } \\
\text { increasing the alum dose and/or decreasing pH value. } \\
\text { - CF pretreatment only moderately improved the removal of TOC } \\
\text { because low MW, hydrophilic organic compounds could remain in } \\
\text { dissolved form after CF. }\end{array}$ & $\begin{array}{l}\text { Xie et al., } \\
2008\end{array}$ \\
\hline $\begin{array}{l}\text { Textile } \\
\text { wastewater, } \\
\text { Korea }\end{array}$ & $\begin{array}{l}\mathrm{CF} \text { (PACl and } \\
\mathrm{FeCl}_{3} \text { as } \\
\text { flocculants) }\end{array}$ & $\begin{array}{l}\text { Dead-end } \\
\text { regenerated } \\
\text { cellulose UF } \\
(\mathrm{MWCO} 100 \\
\mathrm{kDa})\end{array}$ & $\begin{array}{l}\text { The types and dosages of coagulants applied affected the flux } \\
\text { decline drastically during the UF treatment of textile wastewater. } \\
\text { Flux decline was mitigated when the dosage of } \mathrm{FeCl}_{3} \text { increased up } \\
\text { to } 0.5 \mathrm{mM} \text { as } \mathrm{Fe} \text {, whereas PACl was found to control the flux } \\
\text { decline most effectively for low ionic-strength wastewater at a low } \\
\text { dosage of } 0.0371 \mathrm{mM} \text { as } \mathrm{Al} \text {. } \\
\text { - The larger PACl dosages ( }>0.1 \mathrm{mM} \text { as } \mathrm{Al}) \text { induced the reduction } \\
\text { in UF permeability, because the cake layer formed exhibited dual } \\
\text { functions (acting as a protective barrier for membrane fouling and } \\
\text { providing additional resistance to permeation). }\end{array}$ & $\begin{array}{l}\text { Lee et al., } \\
2009\end{array}$ \\
\hline $\begin{array}{l}\text { Biologically } \\
\text { treated landfill } \\
\text { leachate, Turkey }\end{array}$ & PAC & $\begin{array}{l}\text { Crossflow MF } \\
\text { membranes } \\
\text { (pore size } 0.2 \\
\text { and } 0.45 \mu \mathrm{m} \text { ) }\end{array}$ & $\begin{array}{l}\text { - Low pore size }(0.2 \mu \mathrm{m}) \mathrm{MF} \text { hindered pore clogging at the } \\
\text { membrane surface at Low PAC dosage }(<1 \mathrm{mg} / \mathrm{L}) \text {. } \\
\text { - With increasing PAC concentrations (from } 2 \text { to } 8 \mathrm{mg} / \mathrm{L}) \text {, the flux } \\
\text { values increased gradually for both sizes of MF. When } 8 \mathrm{~g} / \mathrm{L} \text { of } \\
\text { PAC was used, PAC-MF hybrid system was efficient in COD } \\
\text { removal and satisfied Cod discharge limit value }(700 \mathrm{mg} / \mathrm{L}) \text {. }\end{array}$ & $\begin{array}{l}\text { Ince et al., } \\
2010\end{array}$ \\
\hline
\end{tabular}


Polymeric flocculants, because of their natural inertness to $\mathrm{pH}$ changes, low dosage, and easy handling, have become very popular in wastewater treatment (Singh et al., 2000). The common synthetic ones include inorganic polymers such as PACl, PAFC (polymeric aluminum ferric chloride) and PFS (polymeric ferric sulfate), as well as organic polymers such as PAM (polyacrylamide), while the common natural organic polymer is Chitosan.

The natural based flocculants (NBFs) are environmental friendly and biodegradable, as well as present good flocculating ability. They can minimize environmental and health risks and have attracted more attention in water and wastewater treatment. The advantages of NBFs are: (a) virtually toxic free; (b) biodegradable in the environment; (c) the raw products are often locally available, whereas industrialized flocculants may not be; and (d) the sludge from flocculation may be reused. The common NBFs can be processed from various sources of starches, such as potato, corn, cassava, arrowroot and yams. These starch-based flocculants (SBFs) can be nonionic, cationic or anionic, depending on the forms of processing and the substitutions (Xing et al., 2010).

In MBRs, as the main objective of the membranes is to filter the sludge mixed liquor, the properties of the mixed liquor govern the filterability and the membrane fouling. Wu et al. (2006) studied the changes of properties (e.g., specific filtration resistance, floc size, supernatant TOC and zeta potential) of activated sludge mixed liquor after addition of monomeric and polymeric flocculants (alum, $\mathrm{FeCl}_{3}, \mathrm{PACl}$, PAFC and PFS). It was found that among the selected flocculants, PFS was the most effective flocculant in controlling membrane fouling; the optimal dose was $1.05 \mathrm{mM} \mathrm{Fe}$. Polymeric flocculants had a better effect on filterability enhancement of mixed liquor than monomeric flocculants. The reason was polymeric flocculants could supply more positive charges and long chain molecules for organic particles and sludge flocs, thereby enhancing the functions of charge neutralization and resulting in higher removal of supernatant organic matter and enlargement of sludge floc size. When polymeric flocculants (PACl, PFS and PAFC) were added in a SMBR, they could control membrane fouling by reducing the initial TMP and the TMP increase rate. Three functions of polymeric flocculants on membrane fouling control were proposed:

- $\quad$ restraining the formation of a gel layer;

- decelerating the development of foulants; and

- $\quad$ removing stable foulants from the membrane surface.

Similarly, Koseoglu (2008) conducted batch shaker tests to evaluate the effectiveness of 7 different flocculants [i.e., three cationic polymers (MPL30, MPE50, $\mathrm{KD} 452)$, a natural polymer (Chitosan), a starch and two metal salts $\left.\left(\mathrm{FeCl}_{3}, \mathrm{PACl}\right)\right]$ on filterability and fouling reduction in MBR mixed liquors. The optimum dosages of flocculants were determined in terms of SMP removal. The results elucidated all tested 
flocculants were able to remove SMP at different extent. At their optimum dosages, the cationic polymers MPE50, MPL30 and KD452 provided 96, 80 and 74\% reductions in fouling rates, respectively. $\mathrm{PACl}$ and $\mathrm{FeCl}_{3}$ exhibited the least improvement in fouling rates and TMP values among tested additives. The enhancements in critical flux achieved by MPL30, MPE50, KD452, $\mathrm{FeCl}_{3}, \mathrm{PACl}$, Chitosan, and Starch were 38, 46, $38,14,14,0$, and $22 \%$ in comparison with raw mixed liquor.

Yoon et al. (2005) reported that cationic polymer MPE (membrane performance enhancer, Nalco, USA) could reduce the SMP level significantly. A decrease of the polysaccharide level from $41 \mathrm{mg} / \mathrm{L}$ to $21 \mathrm{mg} / \mathrm{L}$ was observed with $100 \mathrm{mg} / \mathrm{L}$ of MPE50. Another study (Yoon and Collins, 2006) also indicated that $300 \mathrm{mg} / \mathrm{L}$ of MPE50 could increase the long-term daily flux by $150 \%$ of fouled membranes in a small municipal MBR plant. With $400 \mathrm{ppm}$ MPE50, a full-scale municipal MBR plant $\left(2300 \mathrm{~m}^{3} / \mathrm{d}\right)$ could be operated at an average flux of $47.25 \mathrm{~L} / \mathrm{m}^{2} \cdot \mathrm{h}$, which was $39 \%$ higher than the critical flux $\left(34 \mathrm{~L} / \mathrm{m}^{2} \cdot \mathrm{h}\right)$. Hwang et al. (2007) reported that the cake formed on membrane surface exhibited 1.26 times greater porosity than that in the control reactor with the dosing of MPE.

Iversen et al. (2009) investigated two cationic polymers (MPE50 and KD452) and a starch in pilot scale SMBRs. It was found that all the flocculants had no negative impact on the biological performance in terms of COD and $\mathrm{N}$ removal. With flat sheet PVDF MF (pore size $0.2 \mu \mathrm{m}$, constant flux $16 \mathrm{~L} / \mathrm{m}^{2} \cdot \mathrm{h}, 12 \mathrm{~min}$ filtration $/ 3 \mathrm{~min}$ relaxation), both polymers eliminated mainly larger molecules (up to 60\%), polysaccharide (by $55 \%$ ), protein (around 30\%), improve sludge dewaterability by $80 \%$, increased the particle size by $17-19 \%$ and showed a positive effect on membrane performance. Nevertheless, the starch had no impact on the concentration of polysaccharides and proteins in the supernatant. As a result, even though it slightly increased floc sizes $(6.5 \%)$, the starch led to an accelerated fouling behavior because the starch could not bind completely into the floc during the flocculation, and small starch molecules might penetrate the membrane and amplify the fouling.

Ji et al. (2010) examined the effects of adding six types of flocculants (alum, $\mathrm{FeCl}_{3}$, PACl, PFS, Chitosan, PAM) on mitigation of membrane fouling in SMBR (PVDF Flat sheet, pore size $0.22 \mu \mathrm{m}$, constant flux $16 \mathrm{~L} / \mathrm{m}^{2} \cdot \mathrm{h}, 9 \mathrm{~min}$ filtration followed by 1 min relaxation). In terms of filtration enhancement, polymeric flocculants generally exceed monomeric flocculants. The effectiveness index of sustainable filtration time was in the order of PFS $>$ Chitosan $>\mathrm{PAM}>\mathrm{FeCl}_{3}>\mathrm{PACl}>$ alum. Organic polymeric flocculants have significant effects on biomass morphological properties. For the organic flocculants added SMBR, membrane fouling alleviation was mainly due to the decrease in SMP and fractal dimension as well as the increase in average floc size. Inorganic flocculants have strong effects on SMP, EPS, Zeta potential and relative hydrophobicity but weak effects on average floc size and viscosity. For the inorganic flocculants added SMBR, $\mathrm{Fe}^{3+}$ salts were better than $\mathrm{Al}^{3+}$ salts. The lower fouling rate could be mostly 
attributed to the decrease in SMP and surface charge as well as the increase in relative hydrophobicity.

Guo et al. (2010) evaluated the impacts of flocculant addition to a SMBR (Polyethylene hollow fiber MF, pore size $0.1 \mu \mathrm{m}$, constant flux $10 \mathrm{~L} / \mathrm{m}^{2} . \mathrm{h}$, filtrate backwash two times per day for 2-min duration). Three common flocculants $\left(\mathrm{FeCl}_{3}\right.$, $\mathrm{PACl}$ and Chitosan) were tested based on the performance of organic and nutrients removal, respiration test and fouling control. The data showed that all of the flocculants not only could keep high removal efficiencies of DOC and COD (>90\%) compared to SMBR alone, but also exhibited different advantages and disadvantages according to the properties of the flocculants. For instance, inorganic flocculants strongly affected the nitrification process, and organic flocculant addition slightly reduced the phosphorus removal efficiency in the SMBR. After adding $\mathrm{FeCl}_{3}$ and $\mathrm{PACl}, \mathrm{NH}_{4}-\mathrm{N}$ removal decreased to $32 \%$ and $11 \%$, while $\mathrm{T}-\mathrm{N}$ removal decreased to $22 \%$ and $0.5 \%$ respectively. In addition, flocculants addition improved sludge settleability and oxygen transfer to some extent. Organic flocculant obtained more stable sludge volume indexes (SVI) and specific oxygen uptake rates (SOUR) than those of inorganic flocculants. Inorganic flocculants, on the other hand, led to more reduction of SMP present in mixed liquor and lower membrane fouling rates $\left(1.3\right.$ and $2.6 \mathrm{kPa}$ /day for $\mathrm{FeCl}_{3}$ and $\mathrm{PACl}$ respectively).

Ngo and Guo (2009) developed a modified green bioflocculant (GBF) from a natural starch-based cationic flocculant for membrane fouling control and enhanced phosphorus removal in a conventional aerated SMBR (Polyethylene hollow fiber MF, pore size $0.1 \mu \mathrm{m}$, constant flux $10 \mathrm{~L} / \mathrm{m}^{2} \cdot \mathrm{h}$ ) to treat a primary sewage treated effluent for reuse. The long-term operation results showed that the SMBR system could achieve nearly zero membrane fouling at a very low dose of GBF addition $(500 \mathrm{mg} / \mathrm{day})$ with less backwash frequency ( 2 times/day with 2-min duration). The TMP only increased by $2.5 \mathrm{kPa}$ after 70 days of operation. The SMBR could also remove more than $95 \%$ of DOC and $99.5 \%$ of total phosphorus. From the respiration tests, it was evident that GBF not only had no negative impact on nitrogen removal and the nitrification process but also led to high oxygen uptake rate (OUR) (>30 mg O$/ 2 / \mathrm{L}-\mathrm{h})$ and SOUR.

Table 19.6 summarizes some typical fouling control examples of flocculant addition in MBRs during water and wastewater treatment. Overall, with flocculants addition to MBRs, it has been identified that the removal of organic matter and fouling reduction can be accomplished through the combination of three effects: rejection by membrane, biodegradation by microorganisms, and coagulating/flocculating the activated sludge by flocculants. 
Table 19.6 Fouling control of SMBR processes with flocculant addition in water and wastewater treatment.

\begin{tabular}{|c|c|c|c|c|}
\hline Raw water & Flocculant & Membrane & Results of fouling control & References \\
\hline $\begin{array}{l}\text { Synthetic } \\
\text { primary } \\
\text { treated effluent }\end{array}$ & $\begin{array}{l}\text { Cationic } \\
\text { polymeric MPE, } \\
\text { total } 16 \mathrm{mg} / \mathrm{L}-\mathrm{d}, \\
\text { divided into } \\
\text { three times } \\
\text { injection }\end{array}$ & $\begin{array}{l}\text { U-shaped hollow } \\
\text { fiber MF (pore size } \\
0.4 \mu \mathrm{m} \text {, constant } \\
\text { flux of } 25 \mathrm{~L} / \mathrm{m}^{2}-\mathrm{h} \text { ) }\end{array}$ & $\begin{array}{l}\text { The soluble EPS was lower with MPE addition due to a portion } \\
\text { was entrapped and incorporated into the microbial flocs. } \\
\text { Even though the cake was thicker with the addition of MPE, the } \\
\text { membrane fouling was reduced significantly because MPE can } \\
\text { alter the architecture of the cake formed on membrane surface } \\
\text { and increase cake porosity by making uniform distributions of } \\
\text { cake components along the cake depth with respect to bacterial } \\
\text { cell, polysaccharides and proteins. }\end{array}$ & $\begin{array}{l}\text { Hwang et al., } \\
2007\end{array}$ \\
\hline $\begin{array}{l}\text { Synthetic } \\
\text { primary } \\
\text { treated effluent }\end{array}$ & $\mathrm{FeCl}_{3}$ & $\begin{array}{l}\text { U-shaped hollow } \\
\text { fiber PVDF MF } \\
\text { (pore size } 0.2 \mu \mathrm{m} \text {, } \\
\text { constant flux of } 13 \\
\mathrm{~L} / \mathrm{m}^{2}-\mathrm{h} \text { ) }\end{array}$ & $\begin{array}{l}\text { - The addition of Fe at the optimal concentration }(1.2 \mathrm{mM}) \\
\text { significantly improved the filterability of mixed liquor. Besides, it } \\
\text { reduced both SMP with MW }>10 \mathrm{kDa} \text { in the supernatant and the } \\
\text { fraction of small particles in the range } 1-10 \mu \mathrm{m} \text { in the flocs. } \\
\text { - Fe added to the hybrid MBR system interacted with the } \\
\text { negatively charged groups on the EPS and enhanced the } \\
\text { bioflocculation of small particles in the activated sludge. }\end{array}$ & $\begin{array}{l}\text { Zhang et al, } \\
2008\end{array}$ \\
\hline $\begin{array}{l}\text { Surface water } \\
\text { slightly } \\
\text { contaminated } \\
\text { by domestic } \\
\text { wastewater }\end{array}$ & $\begin{array}{l}\text { PACl, two times } \\
\text { per day at } 10 \\
\mathrm{mg} / \mathrm{L}\end{array}$ & $\begin{array}{l}\text { Hollow fiber PVC } \\
\text { UF (pore size } 0.01 \\
\mu \mathrm{m} \text {, constant flux } \\
\text { of } 10 \mathrm{~L} / \mathrm{m}^{2}-\mathrm{h} \text { ) }\end{array}$ & $\begin{array}{l}\text { - PACl addition achieved much higher organic matter removal in } \\
\text { terms of TOC and DOC, corresponding trihalomethanes } \\
\text { formation potential (THMFP) and haloacetic acids formation } \\
\text { potential (HAAFP) removal in comparison with MBR alone. } \\
\text { - PACl addition led to TMP much lower development than that of } \\
\text { MBR, which implies that flocculation in the bioreactor could } \\
\text { mitigate membrane fouling. }\end{array}$ & $\begin{array}{l}\text { Tian et al., } \\
2008\end{array}$ \\
\hline $\begin{array}{l}\text { Synthetic } \\
\text { primary } \\
\text { treated effluent }\end{array}$ & Alum; $\mathrm{FeCl}_{3}$ & $\begin{array}{l}\text { Flat sheet } \\
\text { polyethylene MF } \\
\text { (pore size } 0.4 \mu \mathrm{m} \text {, } \\
\text { constant flux of } 12 \\
\mathrm{~L} / \mathrm{m}^{2}-\mathrm{h} \text { ) }\end{array}$ & $\begin{array}{l}\text { - The addition of alum had positive effects on phosphorus removal } \\
\text { and membrane filtration resistance without any deterioration in } \\
\text { nitrogen removal efficiency. } \\
\text { - } \mathrm{FeCl}_{3} \text { was efficient in the reduction of specific resistance, but it } \\
\text { led to decrease in pH than that of alum. }\end{array}$ & $\begin{array}{l}\text { Song et al., } \\
2008\end{array}$ \\
\hline $\begin{array}{l}\text { Domestic } \\
\text { wastewater }\end{array}$ & $\begin{array}{l}\text { PFS with } 1.0 \\
\mathrm{mM} \mathrm{Fe}\end{array}$ & $\begin{array}{l}\text { Hollow fiber } \\
\text { polyethylene MF } \\
\text { (pore size } 0.4 \mu \mathrm{m} \text {, } \\
\text { constant flux of } 15 \\
\mathrm{~L} / \mathrm{m}^{2}-\mathrm{h} \text { ) }\end{array}$ & $\begin{array}{l}\text { The addition of PFS formed a gel layer on membrane by } \\
\text { removing organics with high molecular weight from supernatant, } \\
\text { resulting in improving membrane filterability of the mixed liquor. }\end{array}$ & $\begin{array}{l}\text { Wu and } \\
\text { Huang, } 2008\end{array}$ \\
\hline
\end{tabular}




\subsection{Fouling Control for High Pressure Membrane (HPM) Processes}

\subsubsection{Fouling of HPMs}

Fouling of HPMs is usually classified into four major types: colloidal fouling, organic fouling, inorganic fouling/scaling, biofouling and degradation of the membrane itself. The objective of pretreatment to an RO or NF system is to remove particles, reduce organics, and provide a feed that will not cause biofouling in the NF/RO elements. In contrast to scaling and adsorption of small organic solutes which can penetrate into the membrane, biofouling is not a specific problem for NF owing to bacteria are too large and can remain in the superficial biofilm (van der Bruggen et al., 2008; Pearce, 2007b; Abdel-Jawad et al., 2002). For NF of wastewater, the biofilms were found to have a thickness of 20-30 $\mu \mathrm{m}$ (Ivnitsky et al., 2007). The most common scalants for NF are calcium carbonate, gypsum, barium/strontium sulphate and silica.

On the other hand, biofouling and organic fouling can become the dominant fouling in RO applications and more difficult to control in surface water and wastewater applications. In particular, as biofilm formation is a result of the inevitable microflora in the feed and the nutrients present, biofouling is arguably the major challenge when using $\mathrm{RO}$ for the reclamation of municipal effluents. In seawater RO (SWRO) desalination, organic fouling will not be as severe as that in a high recovery municipal wastewater reverse osmosis (MWRO) process due to relatively low organic components in seawater. In MWRO reclamation, phosphate and carbonate salts are dominant precipitates when feed water is secondary effluent without nutrient removal, even though the degrees of saturation of various sparingly soluble substances are much less than those in the SWRO process (Xie et al., 2004; Sadr Ghayeni et al., 1996).

HPM (NF and RO) technologies are being applied to sea water, surface water, groundwater and wastewater for desalination, softening and contaminant removal. However, source waters that have substantially more suspended solids and dissolved substances may not be compatible with HPM systems due to the excess fouling of membranes. Moreover, seasonal factors, climate conditions and activities may also cause water quality variability, which makes HPM more susceptible to fouling. Although the problem can be controlled by cleaning procedures, they are costly in chemicals and downtime. Therefore, proper pretreatment plays a critical role in the performance, life expectancy and the overall operating costs of HPM systems (AMTA, 2010). A number of effective pretreatment processes such as $\mathrm{CF}, \mathrm{SF}$, GAC filters, disinfection, ozonation or $\mathrm{UV} / \mathrm{H}_{2} \mathrm{O}_{2}$ oxidation, flotation, media filtration, softening and/or ion exchange, or other membrane processes (i.e., MF and UF) are fundamental to guarantee a good and constant performance of NF and RO systems (Capar et al., 2006)

\subsubsection{Fouling Control for HPMs}


NF can either be used to treat all kinds of water including ground, surface, and wastewater or used as a pretreatment for desalination. Drinking water production is the largest application of NF in terms of volumes. Besides removal of pesticides, some micropollutants, metals, NOM and DBP precursors, NF membranes have been shown to be able to remove turbidity, microorganisms and hardness, as well as a fraction of the dissolved salts. In wastewater treatment, the potential of NF providing a sufficient good quality permeate for reuse in the process is also noteworthy. NF has been proved to be an efficient and ecologically suited technology for decontamination and recycling of wastewater generated in many industries such as textile industry, food industry, landfill leachate, chemical processing industry and pharmaceutical industry (van der Bruggen et al., 2008; Hilal et al., 2004).

Lee and Lee (2006) investigated the efficiency of pretreatment using MF and UF in river water nanofiltration for drinking water production. NF membranes used were FilmTec NF-45 polyamide membranes with a salt rejection of $40 \%$ for $\mathrm{NaCl}$ at a feed concentration of 2,000 mg/L. Tubular ceramic MF (different pore sizes of $0.08 \mu \mathrm{m}, 0.14$ $\mu \mathrm{m}$ and $0.45 \mu \mathrm{m}$ ) and UF (MWCO $50 \mathrm{kDa}$ and $150 \mathrm{kDa}$ ) membranes (Techsep, France) having a zirconia skin layer were evaluated in a crossflow mode. An analysis of hydraulic resistance indicated that flux loss in NF was attributed to the deposition of small colloids rather than adsorption of dissolved organic matter (DOM). Hydraulic resistances in NF decreased with an increase in fluid velocity, but cake resistance, including polarization and external fouling resistances were still substantial. Pretreatment of raw water using MF/UF was attempted to improve NF flux and mitigate membrane fouling. The NF flux increased with decreasing nominal pore size of the prefilter, suggesting that the size of particles in treated water greatly affects the NF flux. In addition, considering the energy consumption for efficient pretreatment corresponding to permeate volume produced by NF, optimum pretreatment conditions were also suggested. The total specific energy consumed by both NF and pretreatment reaches a minimum value for a certain prefilter pore size: $0.08 \mu \mathrm{m}$ MF under low crossflow conditions and $0.45 \mu \mathrm{m}$ MF under high crossflow conditions, respectively.

Kim et al. (2007) evaluated the influence of pretreatment processes on filtration performance of NF membranes treating untreated river water (with inflow of secondary wastewater treatment effluents) for drinking water production. The three different pretreatment processes are as follows:

(1) MF: In-line $\mathrm{CF}$ ( $\mathrm{PACl}$ as flocculant $)+\mathrm{MF}(0.1 \mu \mathrm{m}$ pore size $)$;

(2) $\mathrm{CS}$ : $\mathrm{CF}$ (polysilicato-iron with a $\mathrm{Si} / \mathrm{Fe}$ ratio of 0.25 ) + sedimentation $+\mathrm{SF}$; and

(3) CSOB: $\mathrm{CF}$ (polysilicato-iron) + sedimentation $+\mathrm{SF}+$ ozonation + biological activated carbon (BAC) adsorption. 
Three flat-sheet polyamide NF membranes with different MWCOs and salt rejections were used. UTC-70 (Toray) has the lowest MWCO (65 Da) and the highest salt rejection $(99.5 \% \mathrm{NaCl})$ which can be classified as a low pressure RO. UTC-60 (Toray) has an intermediate MWCO of $150 \mathrm{Da}$ and a low salt rejection $(45-55 \% \mathrm{NaCl})$ while NF-270 (Dow/FilmTec) has the highest MWCO (200-300 Da) and intermediate salt rejection $\left(40-60 \% \mathrm{CaCl}_{2}\right.$ ). According to 100 -h filtration tests, MF pretreatment was more effective in reducing particles than in removing dissolved organic matter in the raw water. The initial filtration resistances of UTC-70 increased with filtration time for raw water and MF pretreated water due to the adsorption of hydrophilic organic matter rather than cake layer formation, while the resistances for CS and CSOB water remained almost constant during the operation. For UTC-60 (intermediate MWCO) and NF-270 (highest MWCO) membranes, the filtration resistances of the pretreated waters were lower than that of the raw river water. CSOB pretreatment was effective for UTC-70 and UTC-60. However, the very high initial flux of NF-270 in the first $10 \mathrm{~h}$ caused a rapid build-up of a cake layer, resulting in a quick increase of filtration resistance, which indicated that determination of initial flux is very important for the membrane fouling control. Although CSOB pretreatment was the most effective in removing organic foulants, the modified fouling index (MFI) values of CS and CSOB waters showed a similar trend, indicating that ozone and biological activated carbon treatment did not reduce MFI values. The average ratios of organic foulants to the total amounts of foulants on UTC-70 and UTC-60 membranes were in the sequence of raw water (74.5\%) $>$ MF water $(47.5 \%)>\mathrm{CS}$ water $(32.5 \%)>\mathrm{CSOB}$ water $(27.5 \%)$. Furthermore, the order of the inorganic foulants was $\mathrm{CSOB}$ water $>\mathrm{CS}$ water $>\mathrm{MF}$ water $>$ raw water.

Biological filtration can help to minimize organic and biological fouling by removing easily and moderately biodegradable materials together with nutrients. Mosqueda-Jimenez and Huck (2009) determined the effect of biofiltration on the fouling behavior of NF membranes. SN45 (polyamide-urea thin film composite, TriSep, MWCO $200 \mathrm{Da}$ ) and TS80 (aromatic polyamide thin film composite, TriSep) NF membranes were tested. A dual-media anthracite-sand biofilter was used to pretreat synthetic humic acid-laden surface water spiked with a solution of pharmaceutically active compounds. Biofiltration pretreatment was able to reduce the flux decline to one-third or less the values observed with the NF membranes without pretreatment. Moreover, lower organic deposition and microbial counts $(<0.7-\log )$ in the foulant layer were observed for membranes with pretreatment in comparison to membranes without pretreatment. Table 19.7 gives some typical cases of improved performance of NF through different pretreatment processes. 
Table 19.7 Fouling control of pretreatment-NF processes in water and wastewater treatment.

\begin{tabular}{|c|c|c|c|c|}
\hline Raw water & Pretreatment & NF membrane & Results of fouling control & References \\
\hline $\begin{array}{l}\text { Biologically } \\
\text { treated textile } \\
\text { wastewater, } \\
\text { Spain }\end{array}$ & Ozonation & $\begin{array}{l}\text { Spiral-wound NF } \\
\text { (DK2040, } \\
\text { Osmonics) }\end{array}$ & $\begin{array}{l}\text { A COD removal efficiency of } 43 \% \text { was accomplished with low } \\
\text { ozone doses at } 60 \text { min using three ozone generators of } 4 \mathrm{~g}-\mathrm{O}_{3} / \mathrm{h} \text {. } \\
\text { NF of the sample with the lowest COD }(82 \mathrm{mg} / \mathrm{L}) \text { presented the } \\
\text { lowest flux decline during the process. } \\
\text { - A combination of ozonation and NF results in an increase of } \\
\text { membrane life. }\end{array}$ & $\begin{array}{l}\text { Bes-Pía et } \\
\text { al., } 2004\end{array}$ \\
\hline $\begin{array}{l}\text { Groundwater, } \\
\text { Orange } \\
\text { county, USA }\end{array}$ & $\mathrm{H}_{2} \mathrm{O}_{2} / \mathrm{UV}$ & $\begin{array}{l}\text { Thin-film } \\
\text { composite NF70 } \\
\text { NF membrane } \\
\text { (Dow/FilmTec, } \\
\text { MWCO 200-250 } \\
\text { Da) }\end{array}$ & $\begin{array}{l}\text { - The } \mathrm{H}_{2} \mathrm{O}_{2} / \mathrm{UV} \text { oxidation pretreatment of source water not only } \\
\text { significantly mitigated organic fouling by transforming } \\
\text { humic/hydrophobic NOM fractions and polysaccharides into less } \\
\text { sorbable organic acids, but also exhibited the potential to mitigate } \\
\text { biological fouling. } \\
\text { - The } \mathrm{H}_{2} \mathrm{O}_{2} / \mathrm{UV} \text { oxidation prior to NF showed potential for } \\
\text { improving membrane cleanability due to the lower sorption } \\
\text { affinity of preoxidized NOM, increased amount of organic acid } \\
\text { constituents, and transformation of non-desorbable NOM fractions } \\
\text { into readily desorbable organic substances. }\end{array}$ & $\begin{array}{l}\text { Song et al, } \\
2004\end{array}$ \\
\hline $\begin{array}{l}\text { Biologically } \\
\text { treated textile } \\
\text { wastewater, } \\
\text { Turkey }\end{array}$ & $\begin{array}{l}\text { Activated sludge } \\
(\mathrm{AC})+\text { dead-end } \\
\mathrm{MF}(5 \mu \mathrm{m} \text { pore } \\
\text { size })\end{array}$ & $\begin{array}{l}\text { Flat-sheet NF } 270 \\
\text { membrane (Dow/ } \\
\text { FilmTec, MWCO } \\
200-300 \text { Da) }\end{array}$ & $\begin{array}{l}\text { AC appreciably decreased both color and COD concentration, } \\
\text { while MF removed bacteria and other suspended solids before NF. } \\
\text { The pretreatment efficiently lessened the fouling of downstream } \\
\text { NF. }\end{array}$ & $\begin{array}{l}\text { Sahinkaya et } \\
\text { al., } 2008\end{array}$ \\
\hline $\begin{array}{l}\text { Biologically } \\
\text { treated textile } \\
\text { wastewater, } \\
\text { Tunisia }\end{array}$ & $\begin{array}{l}\text { Electrocoagula- } \\
\text { tion (EC) }\end{array}$ & $\begin{array}{l}\text { Flat sheet } \\
\text { polyamide/polysul } \\
\text { fone based thin } \\
\text { film composite NF } \\
\text { (HL, Osmonics) }\end{array}$ & $\begin{array}{l}\text { Electrochemical treatment removed color and COD while NF was } \\
\text { used to further improve the removal efficiency of the color, COD, } \\
\text { conductivity, alkalinity and TDS. } \\
\text { EC as pre-treatment for NF process improved the quality of } \\
\text { treated textile effluent as well as NF fouling. }\end{array}$ & $\begin{array}{l}\text { Aouni et al., } \\
2009\end{array}$ \\
\hline $\begin{array}{l}\text { Secondary } \\
\text { treated effluent } \\
\text { from WWTP, } \\
\text { Germany }\end{array}$ & PAC & $\begin{array}{l}\text { Capillary NF50 } \\
\text { M10 NF } \\
\text { membrane (Norit } \\
\text { X-Flow, MWCO } \\
200 \mathrm{Da})\end{array}$ & $\begin{array}{l}\text { - The adsorption with PAC }(50 \mathrm{mg} / \mathrm{L}) \text { provided pre-cleaning, which } \\
\text { resulted in a better permeate quality and mitigation of flux decline } \\
\text { due to membrane fouling due to the removal of substances causing } \\
\text { membrane fouling such as EfOM ( } 50-60 \% \text { removal). } \\
\text { - The PAC acted as a filter aid and prevented potential foulants } \\
\text { from getting into contact with the membrane. }\end{array}$ & $\begin{array}{l}\text { Kazner et al., } \\
\text { 2009; Meier } \\
\text { et al., } 2002\end{array}$ \\
\hline
\end{tabular}


Conventional equipment based on granular media filtration has been widely applied as pretreatment for polyamide RO membrane (TriSep). Hu et al. (2005) used biofiltration to control RO biofouling during water reclamation. Activated clay, zeolite, with a particle size of $0.5-2.5 \mathrm{~mm}$, was used as a support medium for the biofilm. Biofiltration was found to be a viable way for AOC and DOC removals, with removal efficiencies of $40-49 \%$ and $35-45 \%$ at an empty bed contact time (EBCT) of $30 \mathrm{~min}$. Operational length was improved from less than $100 \mathrm{~h}$ (without biofiltration) to above $300 \mathrm{~h}$ (with biofiltration). It was also found that using the biofiltration as a pretreatment reduced the biofouling potential. De Gisi et al. (2009) utilized a pretreatment process to treat tannery wastewater with a high chloride concentration. The process was composed of biological activated sludge, sedimentation assisted by CF with polyelectrolyte and SF. After pretreatment, the recovery rate of RO (permeate flowrate/feedwater flowrate ratio) were $61.0 \%, 70.3 \%$ and $74.7 \%$, respectively for 80,85 and 90 bar TMP. Scaling and fouling problems could not be observed during the tests.

Figure 19.2 illustrates a typical physico-chemical pretreatment of secondary effluent followed by RO operation for groundwater recharge (López-Ramírez et al., 2006). The pilot plant (output: $100 \mathrm{~m}^{3} / \mathrm{d}$ ) in Chiclana de la Frontera, Spain consists of $\mathrm{CF}$-lamellar sedimentation (using calcium hydroxide for $\mathrm{pH}$ increase, ferric chloride and anionic flocculant: Pasafloct FI-35), sand filtration, disinfection (with sodium hypochlorite and ultraviolet radiation), antiscaling (Osmoprot S-36, a polyacrilate solution), acidification (until $\mathrm{pH} 5.0$ using hydrochloric acid), cartridge filtration (5 microns) and finally RO. In this study, one cellulose acetate RO membrane (model 4040-MSY-CAB2, Hydranautics) and two thin film polyamide membranes (Permetec PAC-4040-BP for low-pressure operation and Permetec PAC-4040-MBP for very lowpressure operations) were tested. Since secondary effluent had high organic matter content, organic and colloidal matter were mainly responsible for fouling of RO membranes. Due to the adequate pretreatment, the high potential organic and colloidal fouling could be reduced. RO further removed pollutants and micro-pollutants in reclaimed wastewater. Analytical parameters for reclaimed wastewater quality from three RO membranes satisfy the applicable drinking water standards. Consequently, the high quality of reclaimed wastewater guarantees the secondary effluent to be used with safety in groundwater recharge and other reuse applications without restrictions.

Although silt density index (SDI) often fails to predict actual membrane fouling due to their limitation to measure fouling potential by colloidal deposition and organic adsorption, SDI is still an important parameter in design and operation of RO and NF membrane processes for desalination. For wastewater desalination by RO (MWRO), all citations rely on the values of the turbidity in the feedwater as a measure of quality (Abdel-Jawad et al., 2002). Some rely on other parameters such as color, TOC, COD, and suspended solids (SS). Reviewing the water quality objectives in the above citations, the following values are suggested as acceptable levels for operating RO plants using treated sewage effluent: (1) turbidity, 1-5 NTU; (2) SDI, < 5; (3) color-CU, 9-15 (at 408 
$\mathrm{mm}$ ); (4) TOC, 10-20 mg/L; (5) SS, $1-5 \mathrm{mg} / \mathrm{L}$; and (6) COD, 5-10 mg/L. The general pretreatment goals for various potential fouling contaminants for SWRO are partly defined by membrane manufacturers (Sutzkover-Gutman and Hasson, 2010): (a) SDI, < 4; (b) zeta potential, > -30V; (c) TOC, $<3 \mathrm{mg} / \mathrm{L}$; (d) soluble organic matter, $<1 \mathrm{mg} / \mathrm{L}$; (e) oil and grease, $<0.1-0.5 \mathrm{mg} / \mathrm{L}$; and (f) bacterial counts, $<10^{6} \mathrm{CFU} / \mathrm{mL}$. Besides, pretreatment is generally considered to be sufficient for the RO unit when membrane cleaning is limited to 3-4 times per year or less, membrane elements last over 5 years and the productivity and salt rejection are maintained within the expected ranges (AMTA, 2010).

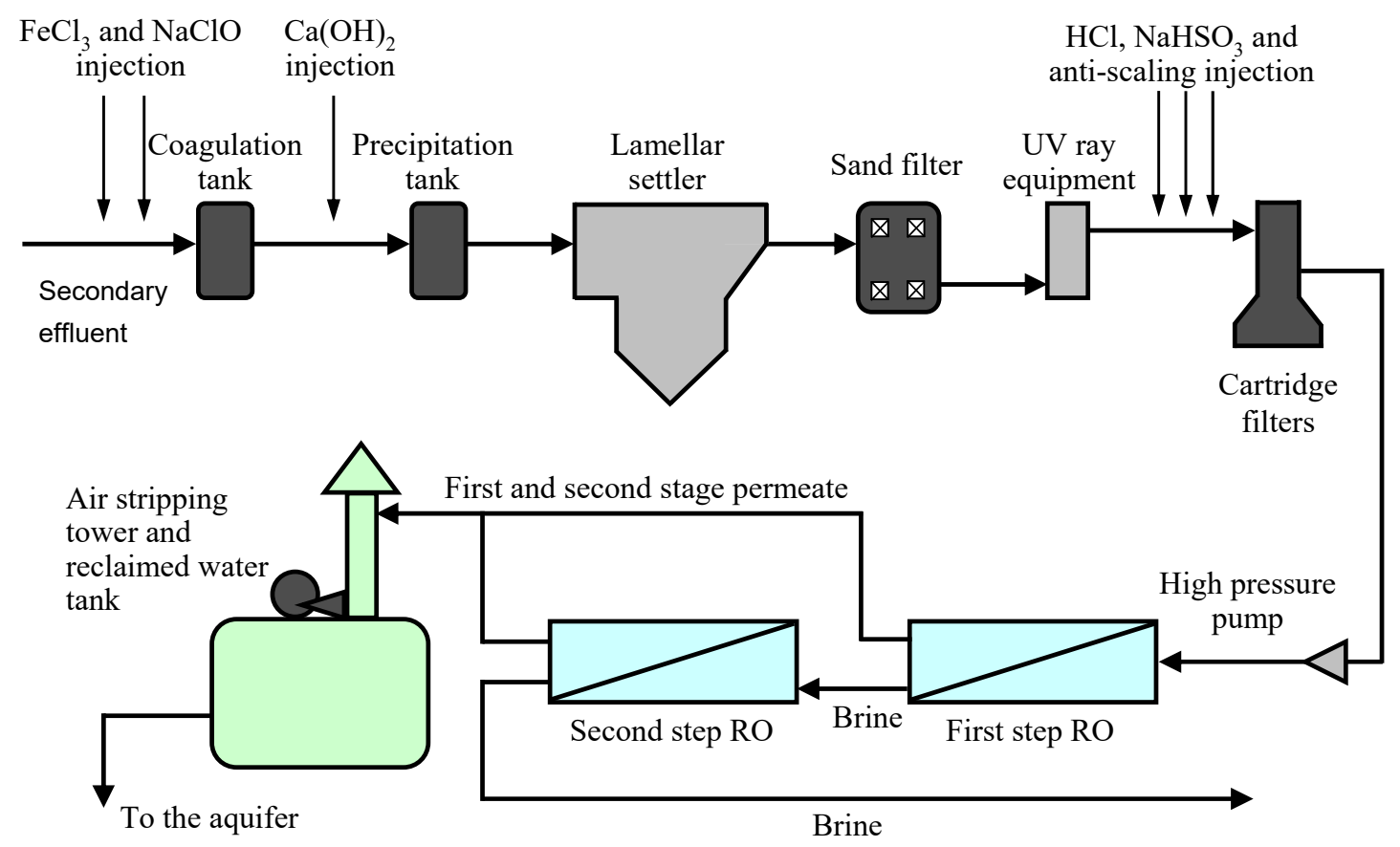

Figure 19.2 Flow diagram of the pilot plant (Redrawn from López-Ramírez et al., 2006).

Since membrane pretreatment prior to RO can significantly reduce fouling potential of variable quality feed water over the conventional pretreatment processes, recent efforts are directed to replacement of granular media filtration by MF/UF membrane filtration. A feasibility study for reclamation of a secondary treated sewage effluent mainly from industrial sources $(60 \%)$ in Singapore has been conducted using a dual membrane UF-RO process (Qin et al., 2006). UF (MWCO $50 \mathrm{kDa}$, Koch) as a pretreatment prior to the thin film polyamide RO (spiral wound LFC1-4040, Hydranautics) not only effectively removed particle foulants as SDI of UF permeate was low at 1.7-2.2 (iron from $0.3-6.4 \mathrm{mg} / \mathrm{L}$ down to $0.03-0.48 \mathrm{mg} / \mathrm{L}$ and turbidity from $1-27.1 \mathrm{NTU}$ down to $0.1-0.6 \mathrm{NTU}$ ), but also reduced a certain amount of organic foulants (TOC removal of 
8-58\%) and phosphate scalants (from $4.8-11.7 \mathrm{mg} / \mathrm{L}$ down to $0.32-7.65 \mathrm{mg} / \mathrm{L}$ ) by dosage of alum. The thin film polyamide composite RO membrane could tolerate organics from industrial wastewater and performed $>96 \%$ salt rejection at the end of the study after 6 months. The study concluded the dual membrane process was capable of reclaiming the sewage effluent mainly from industrial sources for industrial use.

Juang et al. (2007) also examined the application of UF (PVDF, pore size $40 \mathrm{~nm}$ ) pretreatment before the RO process (thin film, pore size $0.3-0.5 \mathrm{~nm}$ ) for water reuse. The biologically treated effluent of industrial park wastewater treatment plant (IPWTP) was purified with $1 \mu \mathrm{m}$ filter before pumping into the UF or/and RO module. The threedimensional AFM (atomic force microscopy) image of the outer surface of the RO membrane indicated that the solute deposited on the valley of the membrane surface indeed decreased the RO membrane surface roughness. The membrane surface roughness of virgin RO, RO pretreated by $1 \mu \mathrm{m}$ filter, and RO pretreated by $1 \mu \mathrm{m} / \mathrm{UF}$ are $140.4,44.4$ and $55.0 \mathrm{~nm}$, respectively. The roughness decrease of RO pretreated by 1 $\mu \mathrm{m} / \mathrm{UF}$ was smaller than that of RO pretreated by $1 \mu \mathrm{m}$ filter because the UF process could remove more colloid materials and organic substance than the 1- $\mu \mathrm{m}$ filter did. As UF pretreatment could remove a small amount of larger organic substance and colloid materials, the initial flux of $1 \mu \mathrm{m} / \mathrm{UF} / \mathrm{RO}$ unit was greater than that of $1 \mu \mathrm{m} / \mathrm{RO}$ unit, and the flux decline of $1 \mu \mathrm{m} / \mathrm{UF} / \mathrm{RO}$ had no significant change during the filtration period.

The effects of MF as pretreatment for $\mathrm{RO}$ on biofouling were analyzed with secondary wastewater effluents from WWTP (Herzberg et al., 2010). MF pretreatment (PVDF, $0.45 \mu \mathrm{m}$, Millipore) reduced permeate flux decline two- to three-fold, while increasing salt rejection. The reduced fouling of the RO (thin film LFC-1, Hydranautics) membrane after pretreatment of the secondary effluent with MF was due to removal of particulate/colloidal matter. Higher oxidative activity and cell viability were observed for the biofouling layer formed during RO treatment of MF pretreated secondary effluents, which indicated the important effect of pretreatment of wastewater effluent on biofilm activity and viability and suggested that pretreatment impacts biofilm mechanic properties and disinfection/cleaning strategies. Additionally, this research suggested that RO membranes treating secondary effluents select for a unique bacterial community irrespective of pretreatment.

Contrary to SWRO with optimal water recovery rates between 30 and $50 \%$, the water recovery rate in wastewater treatment processes must be very high (in many cases almost $100 \%$ ). However, the water recovery rate of RO is limited by scaling, fouling and/or osmotic pressure. Thus, the introduction of NF as a pretreatment is considered a breakthrough for the desalination process (Hilal et al., 2004; Rautenbach et al., 2000). NF pretreatment of seawater in desalination plants: (a) prevented SWRO membrane fouling by the removal of turbidity and bacteria, (b) prevented scaling (both in SWRO and MSF) by removal of scale forming hardness ions and (c) lowered required pressure 
to operate SWRO plants by reducing seawater feed TDS (total dissolved solids) by 30 $60 \%$, depending on the type of NF membrane and operating conditions.

Rautenbach et al. (2000) stated that a combination of NF and high-pressure RO (HPRO) can solve $\mathrm{CaSO}_{4}$ scaling problem and achieve very high water recovery rates in treating multi component solutions such as landfill leachate. At moderate TMP differences of 20-40 bar, NF can split a leachate concentrate into a retentate containing mostly organics and bivalent inorganics such as $\mathrm{CaSO}_{4}$, and into a permeate consisting mostly of chlorides (the reason for high osmotic pressures). Without the danger of scaling, this permeate can be treated by a high-pressure RO.

\subsubsection{Significance of Membrane Pretreatment for HPMs}

The advanced water treatment process based on high pressure microporous membranes such as MF and UF followed by RO has become the industry standard for the treatment of municipal wastewater in indirect potable reuse projects. The benefits of membrane filtration for HPM pretreatment fall into two broad categories, namely reduced cost of the overall system, and improved on-stream time and security of supply (Pearce, 2007b; Durham et al., 2001). The benefits of MF/UF systems as pretreatment compared to conventional systems can be summarized as follows:

- $\quad$ Higher quality of treated water which is largely independent of the feed quality;

- $\quad$ Significantly higher HPM design flux and recovery is normally possible;

- $\quad$ Low space ( $>33 \%$ saving with $\mathrm{MF} / \mathrm{UF}$ );

- $\quad$ RO membrane replacement rate reduced significantly;

- $\quad$ Can treat surface water, with poor and/or variable quality;

- $\quad$ Reduced requirement for RO disinfection and cleaning; and

- Improve the reliability, capital and operating costs of the NF or RO system.

Kim et al. (2002) investigated three pretreatment methods for a spiral-wound RO membrane filtration in order to treat a secondary effluent from a local sewage treatment plant in Singapore ( $70 \%$ of the influent to this plant is industrial wastewater). Three pretreatment systems include: (a) UF; (b) dual media filtration + GAC adsorption; and (c) dual media filtration with dosage of organic flocculant (PAM) and GAC adsorption. It was shown that UF pretreatment yielded the best turbidity removal $(<1.15 \mathrm{NTU})$. When combined with RO, it showed the least flux decline between cleans. In addition, flux recovery was easily achieved with mechanical clean without chemicals. However, the dual media filter + GAC did not provide adequate pretreatment which led to rapid fouling in the RO membrane with a decrease in total dissolved solids rejection (from 78 to $66 \%$ ). The addition of PAM (dosed at $15 \mathrm{mg} / \mathrm{L}$ to form filterable flocs) did not significantly improve the performance of the dual media filtration and GAC either. It was also observed that inadequate pretreatment had an adverse impact on the membrane 
flux recovery by mechanical cleaning. Furthermore, longer chemical cleaning duration was required to recover membrane flux.

Katz and Dosoretz (2008) carried out a work to compare two treatment streams (activated sludge $+\mathrm{CF}+\mathrm{MF}$ and CF-SMBR) in terms of phosphate removal from wastewater effluents as a pretreatment for MWRO (TW30-2514, Dow/FilmTec). Crossflow MF was done on a Memtek (USA) unit equipped with parallel polypropylene hollow fiber membrane modules (pore size $0.2 \mu \mathrm{m}$ ) while SMBR was equipped with hollow fiber UF membrane (ZW-10, Zenon, MWCO $0.04 \mu \mathrm{m}$ ). Sodium aluminate (SAL) was used as flocculant $(20-30 \mathrm{mg} / \mathrm{L})$ because besides being able to remove phosphate and reduce alkalinity, CF was able to remove dissolved natural organic matter and other colloids, and especially humic substances. The results showed that both pretreatment streams achieved almost complete phosphate removal $(\geq 99 \%)$. However, the simultaneous CF-SMBR, which in addition to complete phosphate removal produced higher quality effluents, reduced the effect of calcium carbonate scaling, and displayed a significant reduction of alkalinity $(75 \%)$, turbidity $(99 \%)$ and TOC $(90 \%)$, as compared to activated sludge $+\mathrm{CF}+\mathrm{MF}(28 \%, 29 \%$ and $17 \%$, respectively). Furthermore, the CFSMBR showed no detrimental effects on membrane performance or biological activity and avoided the need of an additional sedimentation or filtration step prior to RO. Thus, the CF-SMBR process seems to be a technically feasible pretreatment of domestic effluents for further RO desalination, generating soft effluents with low content of organic matter and nutrients.

A pilot-plant study was designed to compare the effectiveness of MF and UF as pretreatment for HPMs in reclamation of biologically treated wastewater effluent (Kim et al., 2008). Granular media filtered secondary effluent from the North Buffalo Wastewater Reclamation Facility (Greensboro, NC, USA) was fed to MF and UF units that operated in parallel (Figure 19.3). Filtrate from the MF (CMF 6M10C, $0.2 \mu \mathrm{m}$, US Filter Memcor) and UF (HYDRAcap 60, MWCO $150 \mathrm{kDa}$, Hydranautics) modules passed into the break tank from which the filtrate was pumped into HPMs as feedwater. Three spiral-wound elements of thin film composite HPMs were used. Two were RO membranes (Hydranautics ESPA2, MWCO 250-500 Da and TriSep X20, MWCO 50$100 \mathrm{Da}$ ) and one was NF membrane (Dow/Film Tech NF90, MWCO $300 \mathrm{Da}$ ). All three membranes were formed from polyamide that imparts a negative surface charge. The decline in specific flux was substantially lower for HPMs receiving UF pretreated effluent than MF pretreated effluent. Similarly, the removal of DOC was higher by UF than MF pretreatment (about $15 \%$ by UF compared with $11 \%$ by MF). Membrane autopsies showed less foulant accumulation (35-56\% less) on HPMs by UF pretreatment than by MF pretreatment that suggested possible explanations for less flux decline of the HPMs receiving UF pretreatment. The accumulation of polysaccharides was $27-38 \%$ less on UF pretreated membranes than on MF pretreated membranes. In brief, less fouling of HPMs pretreated by UF than MF could be due to the following reasons: (a) a small, but very important, colloidal fouling fraction must have passed through MF but 
was rejected by UF pretreatment; (b) organic fouling was not related to organics in either the MF or UF filtrates but rather to organics that were generated in situ by microbial activity on the membrane surface; and/or (c) less passage of colloidal Al-P that carried over from secondary wastewater treatment.

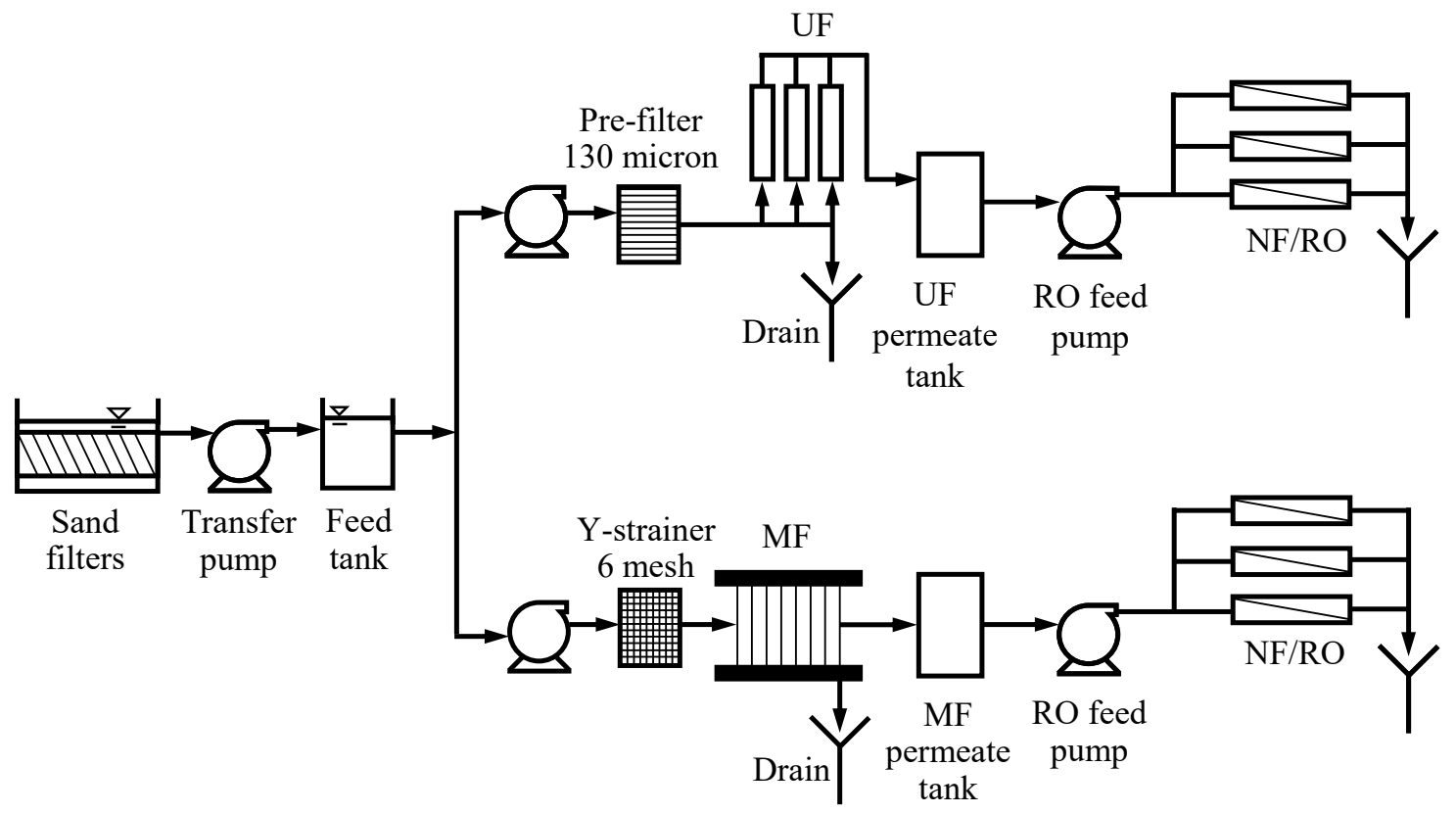

Figure 19.3 Process flow diagram of membrane pilot plant to treat granular media filtered secondary effluent (Redrawn from Kim et al., 2008).

In wastewater treatment, membranes are accepted in all markets for wastewater pretreatment. MF/UF as pretreatment can provide much better RO feed quality than conventional treatment and remove particles and organics through the use of flocculant. Durham et al. (2001) reviewed the benefits of wastewater reuse for industrial and municipal applications using MF pretreatment for the MWRO process. A pilot-scale demonstration plant has been undertaken at Water Factory 21, Orange County, California to compare the conventional pretreatment system with MF followed by RO. MF pretreatment provided approximately $60-70 \%$ improvement in reduction of turbidity and bacteria of the pretreated water compared to conventional pretreatment. The RO cleaning interval was prolonged from 4-6 weeks with conventional pretreatment to 8-12 months with MF pretreatment. The MF pretreated water achieved a $70-80 \%$ improvement in SDI and always produced SDI results significantly below the minimum cut off value of 3 as recommended by the RO manufacturers, while the conventional system could only produce pretreated water with measured SDI of 5-7. 
In case of surface water treatment, although $\mathrm{MF} / \mathrm{UF}$ as pretreatment improves stability and reliability of RO performance and reduces total water cost, its acceptance varies with location. For seawater, pretreatment construction costs are significant and may reach as much as $10-20 \%$ of the total desalination plant capital costs (SutzkoverGutman and Hasson, 2010). Thus, membrane pretreatment is considered expensive, and is only just beginning to gain acceptance even though improved operating expenses, total water cost and plant on-stream time. Glueckstern et al. (2002) conducted field evaluation of hybrid membrane systems consisting of a backwashable capillary UF membrane pretreatment unit (MWCO $150 \mathrm{kDa}$ ) and a RO seawater unit (spiral wound polyamide) was conducted subsequently at two test sites to treat seawater from surface sources. The first test site was at the Red Sea (Eilat site) and the second test site was on the Mediterranean (Ashdod site). Use of membrane technology as a pretreatment step can improve quality of the surface feed water to a level comparable or better than the water quality from the well water sources. Through UF pretreatment, RO could operate at higher permeate flux and recovery rate thereby improving economics of RO seawater desalting. Both permeate flux and system recovery rate increased considerably without creating membrane fouling conditions. When comparing UF pretreatment with a conventional pretreatment unit (in-line CF followed by media filtration) over the economic factors. Despite the cost of UF pretreatment was higher than the cost of conventional pretreatment. The application of membrane pretreatment in SWRO desalting systems is feasible for sites which require very extensive conventional pretreatment or where wide fluctuation of raw water quality can be expected.

Pearce et al. (2004) assessed the possibility of utilizing UF as an alternative to conventional pretreatment for SWRO plant at Jeddah Port, Red Sea, Saudi Arabia. The UF trial using HYDRAcap module was highly successful in achieving stable membrane permeability (average flux of $95-98 \mathrm{~L} / \mathrm{m}^{2} \cdot \mathrm{h}$ ) with a stable TMP $<20 \mathrm{kPa}$ and a consistent filtrate SDI (average 2.2) when operated under optimized process conditions. Compared to conventional dual media pretreatment, UF further lowered 2 SDI units and reduced fouling potential on the RO by approximately $75 \%$. Case studies at 3 other locations in the Gulf of Mexico, the Red Sea, and the Mediterranean on similar seawater feeds utilizing Hydranautics' UF and RO have shown that the RO has operated for 6 months downstream of UF without the need for cleaning and that no problems have been experienced with RO fouling by dissolved organics passing through the UF. After comparing existing data from the UF pilot unit with conventional pretreatment, the price of UF pretreatment was still a key point. However, the additional costs of UF was reduced by avoidance of downtime or production loss, reduced requirement for RO disinfection and cleaning, as well as reduced cost of RO membrane replacement and footprint.

In a recent study, Pearce (2007c) weighed the performance advantage of MF/UF, and the resulting improvement in $\mathrm{RO}$ costs against the additional capex (capital expenditure) costs of pretreatment. The advantages of MF/UF were examined for a case 
study for an Eastern Mediterranean feed. In the study, it was shown that the additional cost of MF/UF can be paid for simply by the savings on chemicals and consumables. For instance, the additional cost of UF in terms of capex and membrane replacement is 2.9 cents $/ \mathrm{m}^{3}$. However, UF reduces RO replacement, saving 1.2 cents $/ \mathrm{m}^{3}$, and reduces chemical cost for both dosing and RO cleaning. If the RO cleans are reduced from three cleans/y to two cleans/y, the saving amounts to 1.7 cents $/ \mathrm{m}^{3}$, which with the RO replacement saving pays for the MF/UF. If two cleans are saved, UF becomes cheaper than conventional pretreatment by 0.7 cents $/ \mathrm{m}^{3}$. In addition, MF/UF brings other potential benefits arising from the $33 \%$ space saving of MF/UF, and the opportunity to increase RO flux and recovery.

In conclusion, potential benefits of membrane pretreatment are claimed to be in higher RO fluxes, increased RO recovery, increased SDI, reduced foulants, guaranteed operation and on-stream time, longer RO membrane life, cost savings in chemical, lower energy costs, increased plant availability and smaller plant footprint.

\subsection{Conclusion}

The principal limitation of membrane filtration processes and MBRs lies in membrane fouling which is mainly associated with the accumulation of inorganic particles, organic compounds and bacteria on the external and/or inner surfaces of the membrane. Membrane fouling affects the quantity and quality of the water produced, the reliability of water production and the costs. In addition, problems induced by membrane fouling include higher operation costs, higher energy demand, increase in cleaning, and irreversible membrane elements damage. Thus, the use of membrane processes combined with different pretreatment options can offer efficient membrane fouling control and high-quality effluent over a wide range of raw water sources.

The design and selection of a pretreatment system is largely depends on the source of the feed water, the nature of the potentially pollutants, membrane materials, module configuration, operation conditions and treated water quality requirement. The most common types of pretreatment for membrane processes employed in water and wastewater treatment include the following: adsorption, $\mathrm{CF}$ with or without sedimentation, preoxidation, media or membrane filtration (MF/UF), and ion exchange. Adsorption and ion exchange are excellent in removing low MW organic compounds, while CF is widely used as a simple and effective means for the removal of particulates, colloids, DBP precursors and high MW organic materials from water and wastewater. Preoxidation associated with AOPs have been successfully utilized in reduction of NOM, nonbiodegradable and refractory organic compounds, etc. Fouling reduction by preoxidation is attributed to the breakdown of the membrane foulants to lower MW compounds. 
Granular media biofiltration can be effectively used as a pretreatment to control organic and biofouling of HPM membranes. Compared to conventional media filtration processes, the applications of LPM filtration as pretreatment have been demonstrated to provide excellent pretreatment to RO in reusing municipal/industrial wastewater effluent and seawater desalination. In particular, LPM techniques (MF/UF) have been considered as cost-effective pretreatment options for higher permeate flux, removal of particulates, producing filtrate free of turbidity and bacteria. Based on savings in RO replacement costs, chemicals, and cleaning downtime, MF/UF as pretreatment for the RO process has been a promising option for seawater, surface water and wastewater application over conventional pretreatment. Furthermore, CF can always be used to assist membrane processes achieving better fouling control and performance. Besides, the popular and promising option for MBR fouling reduction is enhanced $\mathrm{CF}$ with the activated sludge by adding flocculants, increasing the floc size and decreasing concentration of soluble foulants in the bulk phase.

In summary, there is not a single solution for membrane fouling control. The acceptable and proper pretreatment to attain continuous, consistent and reliable operation of the membranes needs to be compatible with overall cost and benefits of pretreatment itself.

\subsection{References}

Abdel-Jawad, M., Al-Shammari, S., and Al-Sulaimi, J. (2002). "Non-conventional treatment of treated municipal wastewater for reverse osmosis." Desalination, $142,11-18$.

Al-Bastaki, N., and Banat, F. (2004). "Combining ultrafiltration and adsorption on bentonite in a one-step process for the treatment of colored waters." Resources, Conservation and Recycling, 41(2), 103-113.

Al-Malack, M. H., and Anderson, G. K. (1996). "Coagulation-crossflow microfiltration of domestic wastewater." Journal of Membrane Science, 121, 59-70.

Amirtharajah, A., and O'Melia, C. R. (1991). "Coagulation Processes: Destabilization, mixing and flocculation." Water Quality and Treatment. $4^{\text {th }}$ Edition, AWWA, Pontius, F. W. (Tech. Ed.), McGraw-Hill Companies, Inc., New York.

AMTA (American Membrane Technology Association) 2010. Membrane Technology Facts: Pretreatment for Membrane Processes. Available at http://www.amtaorg. com/amta media/pdfs/12 Pretreatment.pdf. (Accessed on November 15, 2010).

Aouni, A., Fersi, C., Ali, M.B.S., and Dhahbi, M. (2009). "Treatment of textile wastewater by a hybrid electrocoagulation/nanofiltration process." Journal of Hazardous Materials, 168, 868-874. 
AWWA Membrane Technology Research Committee (1992). "Committee report: membrane processes in potable water treatment." American Water Works Association Journal, 84(1), 59-67.

Badawy, M.I., Ghaly, M.Y., and Gad-Allah, T.A. (2006). "Advanced oxidation processes for the removal of organo-phosphorus pesticides from wastewater." Desalination, 194, 166-175.

Baek, S.O., and Chang, I.S. (2009). "Pretreatments to control membrane fouling in membrane filtration of secondary effluents." Desalination, 244, 153-163.

Bai, R., and Leow, H.F. (2002). "Microfiltration of activated sludge wastewater - the effect of system operation parameters." Separation and Purification Technology, 29, 189-198.

Bennett A. (2005). "Membranes in industry: facilitating reuse of wastewater." Filtration \& Separation, 42(8), 28-30.

Bennett, A. (2007). "High purity water: Advances in ion exchange technology." Filtration \& Separation, 44(6), 20-23.

Bérubé, P.R., Mavinic, D.S., Hall, E.R., Kenway, S.E., and Roett, K. (2002). "Evaluation of adsorption and coagulation as membrane pretreatment steps for the removal of organic material and disinfection-by-product precursors." Journal of Environmental Engineering \& Science, 1(6), 465-476.

Bes-Pía, A., Iborra-Clar, A., Mendoza-Roca, J.A., Iborra-Clar, M.I., and AlcainaMiranda, M.I. (2004). "Nanofiltration of biologically treated textile effluents using ozone as a pre-treatment." Desalination, 167, 387-392.

Broeckmann, A., Busch, J., Wintgens, T., and Marquardt, W. (2006). "Modeling of pore blocking and cake layer formation in membrane filtration for wastewater treatment." Desalination, 189, 97-109.

Busca, G., Berardinelli, S., Resini, C., and Arrighi, L. (2008). "Technologies for the removal of phenol from fluid streams: A short review of recent developments." Journal of Hazardous Materials, 160, 265-288.

Capar, G., Yetis, U., and Yilmaz, L. (2006). "Membrane based strategies for the pretreatment of acid dye bath wastewaters." Journal of Hazardous Materials, 135, 423-430.

Chae, S.R., Yamamura, H., Ikeda, K., and Watanabe, Y. (2008). "Comparison of fouling characteristics of two different poly-vinylidene fluoride microfiltration membranes in a pilot-scale drinking water treatment system using precoagulation/sedimentation, sand filtration, and chlorination." Water Research, 42, 2029-2042.

Chiu, T.Y., and James, A.E. (2006). "Sustainable flux enhancement in non-circular ceramic membranes on wastewater using the Fenton process." Journal of Membrane Science, 279, 347-353.

Cohen, Y. (2001). "Biofiltration-the treatment of fluids by microorganisms immobilized into the filter bedding material: a review." Bioresource Technology, 77, 257-274. 
Comninellis, C., Kapalka, A., Malato, S., Parsons, S.A., Poulios, I., and Mantzavinos, D. (2008). "Advanced oxidation processes for water treatment: advances and trends for R\&D." Journal of Chemical Technology \& Biotechnology, 83(6), 769-776.

Cornelissen, E.R., Beerendonk, E.F., Nederlof, M.N., van der Hoek, J.P., and Wessels, L.P. (2009). "Fluidized ion exchange (FIX) to control NOM fouling in ultrafiltration." Desalination, 236, 334-341.

Crittenden, J.C., Trussell, R.R., Hand, D.W., Howe, K.J., and Tchobanoglous, G. (2005). Water Treatment: Principles and Design. $2^{\text {nd }}$ ed., John Wiley \& Sons, Inc., Hoboken, NJ.

De Gisi, S., Galasso, M., and De Feo, G. (2009). "Treatment of tannery wastewater through the combination of a conventional activated sludge process and reverse osmosis with a plane membrane." Desalination, 249, 337-342.

Dialynas, E., and Diamadopoulos, E. (2008). "Integration of immersed membrane ultrafiltration with coagulation and activated carbon adsorption for advanced treatment of municipal wastewater." Desalination, 230, 113-127.

Durham, B., Bourbigot, M.M., and Pankratz, T. (2001). "Membranes as pretreatment to desalination in wastewater reuse: operating experience in the municipal and industrial sectors." Desalination, 138, 83-90.

Ellis, D., Bouchard, C., and Lantagne, G. (2000). "Removal of iron and manganese from groundwater by oxidation and microfiltration." Desalination, 130, 255-264.

Fabris, R., Lee, E.K., Chow, C.W.K., Chen, V., and Drikas, M. (2007). "Pre-treatments to reduce fouling of low pressure micro-filtration (MF) membranes." Journal of Membrane Science, 289, 231-240.

Fan, L., Nguyen, T., Roddick, F.A., and Harris, J.L. (2008). "Low-pressure membrane filtration of secondary effluent in water reuse: Pre-treatment for fouling reduction." Journal of Membrane Science, 320, 135-142.

Fane, A.G., Chang, S., and Chardon, E. (2002). "Submerged hollow fibre membrane module-design options and operational considerations." Desalination, 146, 231236.

Fane, A.G. (2007). "Sustainability and membrane processing of wastewater for reuse." Desalination, 202, 53-58.

Farahbakhsh, K., Svrcek, C., Guest, R.K., and Smith, D.W. (2004). "A review of the impact of chemical pretreatment on low-pressure water treatment membranes." Journal of Environmental Engineering \& Science, 3(4), 237-253.

Feng, F., Xu, Z., Li, X., You, W., and Zhen, Y. (2010). "Advanced treatment of dyeing wastewater towards reuse by the combined Fenton oxidation and membrane bioreactor process." Journal of Environmental Sciences, 22(11), 1657-1665.

Glueckstern, P., Priel, M., and Wilf, M. (2002). "Field evaluation of capillary UF technology as a pretreatment for large seawater RO systems." Desalination, 147, $55-62$.

Goren, U., Aharoni, A., Kummel, M., Messalem, R., Mukmenev, I., Brenner, A., and Gitis, V. (2008). "Role of membrane pore size in tertiary flocculation/adsorption/ 
ultrafiltration treatment of municipal wastewater." Separation and Purification Technology, 61, 193-203.

Guo, W.S. (2005). Microfiltration Hybrid Systems in Wastewater Treatment for Reuse. Ph.D. Dissertation, University of Technology, Sydney, Australia.

Guo, W.S., Ngo, H.H., Vigneswaran, S., Dharmawan, F., Nguyen T.T., and Aryal, R. (2010). "Effect of different flocculants on short-term performance of submerged membrane bioreactor." Separation and Purification Technology, 70, 274-279.

Guo, W.S., Shim, W.G., Vigneswaran, S., and Ngo, H.H. (2005a). "Effect of operating parameters in a submerged membrane adsorption hybrid system: experiments and mathematical modeling." Journal of Membrane Science, 247, 65-74.

Guo, W.S., Vigneswaran, S., and Ngo, H.H. (2005b). "Effect of flocculation and/or adsorption as pretreatment on the critical flux of crossflow microfiltration." Desalination, 172, 53-62.

Guo, W.S., Vigneswaran, S., Ngo, H.H., Xing, W., and Goteti, P. (2008). "Comparison of the performance of submerged membrane bioreactor (SMBR) and submerged membrane adsorption bioreactor (SMABR)." Bioresource Technology, 99, 10121017.

Guo, W.S., Zhang, R., Vigneswaran, S., Ngo H.H., and Kandasamy, J. (2010). "Membranes coupled with physico chemical treatment in water reuse." Water Science and Technology, 61(2), 513-519.

Gültekin, I., and Ince, N.H. (2007). "Synthetic endocrine disruptors in the environment and water remediation by advanced oxidation processes." Journal of Environmental Management, 85, 816-832.

Herzberg, M., Berry, D., and Raskin, L. (2010). "Impact of microfiltration treatment of secondary wastewater effluent on biofouling of reverse osmosis membranes." Water Research, 44, 167-176.

Hilal, N., Al-Zoubi, H., Darwish, N.A., Mohamma, A.W., and Abu Arabi, M. (2004). "A comprehensive review of nanofiltration membranes: Treatment, pretreatment, modelling, and atomic force microscopy." Desalination, 170, 281-308.

Howe, K. J., and Clark, M. M. (2002). "Fouling of microfiltration and ultrafiltration membranes by natural waters." Environmental Science \& Technology, 36(16), 3571-3576.

Hu, J.Y., Song, L.F., Ong, S.L., Phua, E.T., and Ng, W.J. (2005). "Biofiltration pretreatment for reverse osmosis (RO) membrane in a water reclamation system." Chemosphere, 59, 127-133.

Huang, C.P., Dong, C., and Tang, Z. (1993). "Advanced chemical oxidation: Its present role and potential future in hazardous waste treatment." Waste Management, 13(5-7), 361-377.

Huang, H., Schwab, K., and Jacangelo, J.G. (2009). "Pretreatment for low pressure membranes in water treatment: A review." Environmental Science \& Technology, 43(9), 3011-3019. 
Huang, H., Spinette, R., and O’Melia, C.R. (2008). "Direct-flow microfiltration of aquasols: I. Impacts of particle stabilities and size." Journal of Membrane Science, 314, 90-100.

Huang, X., Meng, Y., Liang, P., and Qian, Y. (2007). "Operational conditions of a membrane filtration reactor coupled with photocatalytic oxidation." Separation and Purification Technology, 55, 165-172.

Huang, X., Leal, M., and Li, Q. (2008). "Degradation of natural organic matter by $\mathrm{TiO} 2$ photocatalytic oxidation and its effect on fouling of low-pressure membranes." Water Research, 42, 1142-1150.

Hwang, B.K., Lee, W.N., Park, P.K., Lee, C.H., and Chang, I.S. (2007). "Effect of membrane fouling reducer on cake structure and membrane permeability in membrane bioreactor." Journal of Membrane Science, 288, 149-156.

Hwang, K.J., and Hsueh, C.L. (2003). "Dynamic analysis of cake properties in microfiltration of soft colloids." Journal of Membrane Science, 214, 259-273.

Ince, M., Senturk, E., Onkal Engin, G., and Keskinler, B. (2010). "Further treatment of landfill leachate by nanofiltration and microfiltration-PAC hybrid process." Desalination, 255, 52-60.

Iversen, V., Mehrez, R., Horng, R.Y., Chen, C.H., Meng, F., Drews, A., Lesjean, B., Ernst, M., Jekel, M., and Kraume, M. (2009). "Fouling mitigation through flocculants and adsorbents addition in membrane bioreactors: Comparing lab and pilot studies." Journal of Membrane Science, 345, 21-30.

Ivnitsky, H., Katz, I., Minz, D., Volvovic, G., Shimoni, E., Kesselman, E., Semiat, R., and Dosoretz, C.G. (2007). "Bacterial community composition and structure of biofilms developing on nanofiltration membranes applied to wastewater treatment." Water Research, 41, 3924-3935.

Jacangelo, J.G., Chellam, S., and Trussell, R.R. (1998). "The membrane treatment." Civil Engineering Magazine, 68(9), 42-45.

Ji, J., Qiu, J., Wai, N., Wong, F.S., and Li, Y. (2010). "Influence of organic and inorganic flocculants on physical-chemical properties of biomass and membrane-fouling rate." Water Research, 44, 1627-1635.

Jirankova, H., Cakl, J., Markvartova, O., and Dolecek, P. (2007). "Combined membrane process at wastewater treatment." Separation and Purification Technology, 58, 299-303.

Juang, L.C., Tseng, D.H., and Lin, H.Y. (2007). "Membrane processes for water reuse from the effluent of industrial park wastewater treatment plant: a study on flux and fouling of membrane." Desalination, 202, 302-309.

Kabsch-Korbutowicz, M., Bilyk, A., and Molczan, M. (2006). "The effect of feed water pretreatment on ultrafiltration membrane performance." Polish Journal of Environmental Studies. 15(5) 719-725.

Kabsch-Korbutowicz, M., Majewska-Nowak, K., and Winnicki, T. (2008). "Water treatment using MIEX ${ }^{\circledR}$ DOC/ultrafiltration process." Desalination, 221, 338-344.

Katz, I., and Dosoretz, C.G. (2008). "Desalination of domestic wastewater effluents: Phosphate removal as pretreatment." Desalination, 222, 230-242. 
Kazner, C., Meier, J., Wintgens, T., and Melin, T. (2009). "Capillary nanofiltration coupled with powdered activated carbon adsorption for high quality water reuse." Water Science and Technology, 60(1), 251-259.

Khan, M.M.T., Jones, W., Camper, A., Takizawa, S., Katayama, H., Kurisu, F., and Ohgaki, S. (2007). "Powdered activated carbon and biofiltration improve MF performance: Part II." Membrane Technology, 2007(6), 7-10.

Kim, H.A., Choi, J.H., and Takizawa, S. (2007). "Comparison of initial filtration resistance by pretreatment processes in the nanofiltration for drinking water treatment." Separation and Purification Technology, 56, 354-362.

Kim, J., DiGiano, F.A., and Reardon, R.D. (2008). "Autopsy of high-pressure membranes to compare effectiveness of MF and UF pretreatment in water reclamation." Water Research, 42, 697-706.

Kim, J.O., Jung, J.T., Yeom, I.T., and Aoh, G.H. (2007). "Electric fields treatment for the reduction of membrane fouling, the inactivation of bacteria and the enhancement of particle coagulation." Desalination, 202, 31-37.

Kim, J.S., Akeprathumchai, S., and Wickramasinghe, S.R. (2001). "Flocculation to enhance microfiltration." Journal of Membrane Science, 182, 161-172.

Kim, S.L., Chen, J.P., and Ting, Y.P. (2002). "Study on feed pretreatment for membrane filtration of secondary effluent." Separation and Purification Technology, 29, 171-179.

Klavarioti, M., Mantzavinos, D., and Kassinos, D. (2009). "Removal of residual pharmaceuticals from aqueous systems by advanced oxidation processes." Environment International, 35(2), 402-417.

Kornboonraksa, T., Lee, H.S., Lee, S.H., and Chiemchaisri, C. (2009). "Application of chemical precipitation and membrane bioreactor hybrid process for piggery wastewater treatment." Bioresource Technology, 100, 1963-1968.

Koseoglu, H., Yigit, N.O., Iversen, V., Drews, A., Kitis, M., Lesjean, B., and Kraume, M. (2008). "Effects of several different flux enhancing chemicals on filterability and fouling reduction of membrane bioreactor (MBR) mixed liquors." Journal of Membrane Science, 320, 57-64.

Kurniawan, T.A., Chan, G.Y.S. Lo, W.H., and Babel, S. (2006). "Physico-chemical treatment techniques for wastewater laden with heavy metals." Chemical Engineering Journal, 118, 83-98.

Kweon, J.H., Hur, H.W., Seo, G.T., Jang, T.R., Park, J.H., Choi, K.Y., and Kim, H.S. (2009). "Evaluation of coagulation and PAC adsorption pretreatments on membrane filtration for a surface water in Korea: A pilot study." Desalination, 249, 212-216.

Lee, B.B., Choo, K.H., Chang, D., and Choi, S.J. (2009). "Optimizing the coagulant dose to control membrane fouling in combined coagulation/ultrafiltration systems for textile wastewater reclamation." Chemical Engineering Journal, 155, 101-107. 
Lee, C.W., Bae, S.D., Han, S.W., and Kang, L.S. (2007). "Application of ultrafiltration hybrid membrane processes for reuse of secondary effluent." Desalination, 202, 239-246.

Lee, J., Ahn, W.Y., and Lee, C.H. (2001). "Comparison of the filtration characteristics between attached and suspended growth microorganisms in submerged membrane bioreactor." Water Research, 35, 2435-2445.

Lee, J.W., Choi, S.P., Thiruvenkatachari, R., Shim, W.G., and Moon, H. (2006). "Submerged microfiltration membrane coupled with alum coagulation/powdered activated carbon adsorption for complete decolorization of reactive dyes." Water Research, 40, 435-444.

Lee, S., and Lee, C.H. (2006). "Microfiltration and ultrafiltration as a pretreatment for nanofiltration of surface water." Separation Science and Technology, 41, 1-23.

Lehman, S.G., and Liu, L. (2009). "Application of ceramic membranes with preozonation for treatment of secondary wastewater effluent." Water Research, 43, 2020-2028.

Li, Q., and Elimelech, M. (2004). "Organic fouling and chemical cleaning of nanofiltration membranes: Measurements and mechanisms." Environmental Science \& Technology, 38(17), 4683-4693.

López-Ramírez, J.A., Coello Oviedo, M.D., and Quiroga Alonso, J.M. (2006). "Comparative studies of reverse osmosis membranes for wastewater reclamation." Desalination, 191, 137-147.

Mantzavinos, D., and Psillakis, E. (2004). "Enhancement of biodegradability of industrial wastewaters by chemical oxidation pre-treatment." Journal of Chemical Technology \& Biotechnology, 79(5), 431-454.

Matsui, Y., Hasegawa, H., Ohno, K., Matsushita, T., Mima, S., Kawase, Y., and Aizawa, T. (2009). "Effects of super-powdered activated carbon pretreatment on coagulation and trans-membrane pressure buildup during microfiltration." Water Research, 43, 5160-5170.

Meier, J., Melin, T., and Eilers, L.H. (2002). "Nanofiltration and adsorption on powdered adsorbent as process combination for the treatment of severely contaminated waste water." Desalination, 146, 361-366.

Mosqueda-Jimenez, D.B., and Huck, P.M. (2009). "Effect of biofiltration as pretreatment on the fouling of nanofiltration membranes." Desalination, 245, 60 72.

Mozia, S. (2010). "Photocatalytic membrane reactors (PMRs) in water and wastewater treatment. A review." Separation and Purification Technology, 73, 71-91.

Mulder, M. (1996). Basic principles of membrane technology. Kluwer Academic Publishers, Dordrecht, The Netherlands.

Mutlu, S.H., Yetis, U., Gurkan, T., and Yilmaz, L. (2002). "Decolorization of wastewater of a baker's yeast plant by membrane processes." Water Research, 36, 609-616.

Neale, P.A., and Schäfer, A.I. (2009). "Magnetic ion exchange: Is there potential for international development?" Desalination, 248, 160-168. 
Ngo, H. H., and Guo, W. S. (2009). "Membrane fouling control and enhanced phosphorus removal in an aerated submerged membrane bioreactor using modified green bioflocculant." Bioresource Technology, 100, 4289-4291.

Nguyen, S.T., and Roddick, F.A. (2010). "Effects of ozonation and biological activated carbon filtration on membrane fouling in ultrafiltration of an activated sludge effluent." Journal of Membrane Science, 363, 271-277.

Oh, B.S., Jang, H.Y., Hwang, T.M., and Kang, J.W. (2007). "Role of ozone for reducing fouling due to pharmaceuticals in MF (microfiltration) process." Journal of Membrane Science, 289, 178-186.

O'Melia, C. R. (1980). Aquasols: the behavior of small particles in aquatic systems. Environmental Science \& Technology. 14(9), 1052-1060.

Panglisch, S., Kraus, G., Tatzel, A., and Lickes, J.P. (2010). "Membrane performance in combined processes including ozonation or advanced oxidation, powdered activated carbon and coagulation - Investigations in pilot scale." Desalination, 250, 819-823.

Park, C., Hong, S.W., Chung, T.H., and Choi, Y.S. (2010). "Performance evaluation of pretreatment processes in integrated membrane system for wastewater reuse." Desalination, 250, 673-676.

Pearce, G., Talo, S., Chida, K., Basha, A., and Gulamhusein, A. (2004). "Pretreatment options for large scale SWRO plants: case studies of UF trials at Kindasa, Saudi Arabia, and conventional pretreatment in Spain." Desalination, 167, 175-189.

Pearce, G. (2007a). "Introduction to membranes: Fouling control." Filtration \& Separation, 44(6), 30-32.

Pearce, G. (2007b). "Introduction to membranes: Water and wastewater-RO pretreatment." Filtration \& Separation, 44(7), 28-31.

Pearce, G.K. (2007c). "The case for UF/MF pretreatment to RO in seawater applications." Desalination, 203, 286-295.

Qin, J.J., Wai, M.N., Oo, M.H., Kekre, K.A., and Seah, H. (2006). "Feasibility study for reclamation of a secondary treated sewage effluent mainly from industrial sources using a dual membrane process." Separation and Purification Technology, 50, 380-387.

Ryu, J., Choi, W., and Choo, K.H.(2005). "A pilot-scale photocatalyst-membrane hybrid reactor: performance and characterization." Water Science and Technology, 51(6-7), 491-497.

Sadr Ghayeni, S.B., Madaeni, S.S., Fane, A.G., and Schneider, R.P. (1996). "Aspects of microfiltration and reverse osmosis in municipal wastewater reuse." Desalination, $106,25-29$.

Sahinkaya, E., Uzal, N., Yetis, U., and Dilek, F.B. (2008). "Biological treatment and nanofiltration of denim textile wastewater for reuse." Journal of Hazardous Materials, 153, 1142-1148.

Schippers, J.C., Kruithof, J., and Nederlof M. (2004). Integrated membrane systems. AWWA Research Foundation and American Water Works Association, Elbert, Colorado. 
Seidel, A., and Elimelech, M. (2002). "Coupling between chemical and physical interactions in natural organic matter (NOM) fouling of nanofiltration membranes: implications for fouling control." Journal of Membrane Science, 203, 245-255.

Sheikholeslami, R. (1999). "Fouling mitigation in membrane processes." Desalination, $123,45-53$.

Shih, I.L., Van, Y.T., Yeh, L.C., Lin, H.G., and Chang, Y.N. (2001). "Production of a biopolymer flocculant from Bacillus licheniformis and its flocculation properties." Bioresource Technology, 78, 267-272.

Singh, R.P., Karnakar, G.P., Rath, S.K., Karmakar, N.C., Pandey, S.R., Tripathy, T., Panda, J., Kanan, K., Jain, S.K., Lan, N.T. (2000). "Biodegradable drag reducing agents and flocculants based on polysaccharides: material and application." Polymer Engineering and Science, 40, 46-60.

Singer, P.C., and Reckhow, D.A. (1999). "Chemical Oxidation." Water quality and treatment: a handbook of community water supplies. Letterman, R.D. (Ed.), McGraw-Hill, New York.

Song, K.G., Kim, Y., and Ahn, K.H. (2008). "Effect of coagulant addition on membrane fouling and nutrient removal in a submerged membrane bioreactor." Desalination, 221, 467-474.

Song, W., Ravindran, V., Koel, B.E., and Pirbazari, M. (2004). "Nanofiltration of natural organic matter with $\mathrm{H}_{2} \mathrm{O}_{2} / \mathrm{UV}$ pretreatment: fouling mitigation and membrane surface characterization." Journal of Membrane Science, 241, 143160.

Speth, T.F., Summers, R.S., and Gusses, A.M. (1998). "Nanofiltration foulants from a treated surface water." Environmental Science \& Technology, 32, 3612-3617.

Sutzkover-Gutman, I., and Hasson, D. (2010). "Feed water pretreatment for desalination plants." Desalination, 264, 289-296.

Tanaka, T., Usui, K., and Nakanishi, K. (1998). "Formation of the gel layer of polymers and its effect on the permeation flux in crossflow filtration of Corynebacterium glutamicum broth." Separation Science and Technology, 33(5), 707-722.

Tian, J.Y., Liang, H., Li, X., You, S.J., Tian, S., and Li, G.B. (2008). "Membrane coagulation bioreactor (MCBR) for drinking water treatment." Water Research, 42, 3910-3920.

Van der Bruggen, B., Curcio, E., and Drioli, E. (2004). "Process intensification in the textile industry: the role of membrane technology." Journal of Environmental Management, 73(3), 267-274.

Van der Bruggen, B., Mänttäri, M., and Nyström, M. (2008). "Drawbacks of applying nanofiltration and how to avoid them: A review." Separation and Purification Technology, 63, 251-263.

Wend, C.F., Stewart, P.S., Jones, W., and Camper, A.K. (2003). "Pretreatment for membrane water treatment systems: a laboratory study." Water Research, 37, $3367-3378$. 
Wikipedia (The Free Encyclopedia) (2010). Ion exchange. Available at http://en.wikipedia.org/wiki/Ion_exchange. (Accessed on November 27, 2010).

Wu, J., Chen, F., Huang, X., Geng, W., and Wen, X. (2006). "Using inorganic coagulants to control membrane fouling in a submerged membrane bioreactor." Desalination, 197, 124-136.

Wu, J.L., and Huang, X. (2008). "Effect of dosing polymeric ferric sulfate on fouling characteristics, mixed liquor properties and performance in a long-term running membrane bioreactor." Separation and Purification Technology, 63, 45-52.

Xie, R.J., Gomez, M.J., Xing, Y.J., and Klose, P.S. (2004). "Fouling assessment in a municipal water reclamation reverse osmosis system as related to concentration factor." Journal of Environmental Engineering and Science, 3(1), 61-72.

Xie, X., Zhou, H., Chong, C., and Holbein, B. (2008). "Coagulation assisted membrane filtration to treat high strength wastewater from municipal solid waste anaerobic digesters." Journal of Environmental Engineering and Science, 7(1), 21-28.

Xing, W., Guo, W. S., Ngo, H. H., Cullum, P., and Listowski, A. (2010). "Integration of inorganic micronutrients and natural starch based cationic flocculant in primary treated sewage effluent (PTSE) treatment." Separation Science and Technology, 45(5), 619-625.

Yoon, S.H., and Collins, J.H. (2006). "A novel flux enhancing method for membrane bioreactor (MBR) process using polymer." Desalination, 191, 52-61.

Yoon, S.H., Collins, J.H., Musale, D., Sundararajan, S., Tsai, S.P., Hallsby, G.A., Kong, J.F., Koppes, J., and Cachia, P. (2005). "Effects of flux enhancing polymer on the characteristics of sludge in membrane bioreactor process." Water Science and Technology, 51 (6-7), 151-157.

Zhang, H.F., Sun, B.S., Zhao, X.H., Gao, Z.H. (2008). "Effect of ferric chloride on fouling in membrane bioreactor." Separation and Purification Technology, 63, 341-347.

Zhang, J., Sun, Y., Chang, Q., Liu, X., and Meng, G. (2006). "Improvement of crossflow microfiltration performances for treatment of phosphorus-containing wastewater." Desalination, 194, 182-191.

Zhang, X., Pan, J.H., Du, A.J., Fu, W., Sun, D.D., and Leckie, J.O. (2009). "Combination of one-dimensional $\mathrm{TiO} 2$ nanowire photocatalytic oxidation with microfiltration for water treatment." Water Research, 43, 1179-1186.

Zhou, H., and Smith, D.W. (2002). "Advanced technologies in water and wastewater treatment." Journal of Environmental Engineering and Science, 1, 247-264.

Zhu, X., and Elimelech, M. (1997). "Colloidal fouling of reverse osmosis membranes: measurements and fouling mechanisms." Environmental Science \& Technology, 31(12), 3654-3662.

Zularisam, A.W., Ismail, A.F., and Salim, R. (2006). "Behaviours of natural organic matter in membrane filtration for surface water treatment - a review." Desalination, 194, 211-231. 